\title{
Energy management in industry: a systematic review of previous findings and an integrative conceptual framework
}

\author{
Mike Schulze, Henrik Nehler, Mikael Ottosson and Patrik Thollander
}

\section{Linköping University Post Print}

\section{Tweet}

N.B.: When citing this work, cite the original article.

Original Publication:

Mike Schulze, Henrik Nehler, Mikael Ottosson and Patrik Thollander, Energy management in industry: a systematic review of previous findings and an integrative conceptual framework, 2016, Journal of Cleaner Production, (112), 3692-3708.

http://dx.doi.org/10.1016/j.jclepro.2015.06.060

Copyright: Elsevier

http://www.elsevier.com/

Postprint available at: Linköping University Electronic Press

http://urn.kb.se/resolve?urn=urn:nbn:se:liu:diva-123416 


\title{
Energy management in industry - a systematic review of previous findings and an integrative conceptual framework
}

\begin{abstract}
Current research points to a large energy efficiency potential in industry which is still left unexploited. One of the most promising means of reducing energy consumption and related energy costs is implementing an energy management. This paper provides a systematic review of existing academic journal publications on energy management in industry. Five essential key elements of an energy management based on overarching themes are identified within the body of literature (strategy/planning, implementation/operation, controlling, organization and culture) and the specific findings relating to each key element are synthesized. Subsequently a conceptual framework of an energy management is developed which illustrates that a comprehensive approach is necessary in order to effectively exploit the existing energy efficiency potential. Finally implications for further research are described.
\end{abstract}

Keywords: energy management; energy management system; conceptual framework; energy efficiency; industry; systematic literature review

Word Count: 13,408 words 


\section{Introduction}

Rising energy prices, stricter environmental law restrictions, new supply and demand policies like the European Union Emissions Trading System (EU ETS) as well as energy end-use efficiency policy programs have created increased demand for reducing energy consumption and related energy costs in industrial organizations. In order to position themselves as market leaders within their business in the long run, the management and operation of a company's energy system is of great importance, especially for energy-intensive industries such as pulp and paper, steel and petro-chemicals. Although the industrial sector across all branches has made continuous and successful improvements concerning energy efficiency in the last three decades (International Energy Agency, 2007), a significant share of the potential to improve energy efficiency - more than half located in industry - still remains untapped (International Energy Agency, 2012). This gap between the actual level of energy efficiency and what theoretically could be reached, given that all cost-effective technologies are implemented, is referred to as the energy efficiency gap (Hirst \& Brown, 1990). Recent research also refers to an extended energy efficiency gap, showing that if energy management is also included, the potential for improved energy efficiency is even higher, i.e. including non-technical improvements such as enhanced operations (Backlund et al., 2012). Previous research has emphasized that the reasons for nonimplementation or at least delayed adoption of technically available energy efficient technologies can be explained by the existence of various barriers to energy efficiency (Brunke et al., 2014). The characteristics of many energy-efficient technologies also make implementation a challenge (Fleiter et al., 2012a). Improving energy efficiency in industry is also difficult due to the high complexity of industrial energy systems. Production systems with their related support processes differ between industrial sites, which make generalizability and scale advantage a challenge, since even in a single corporation different sites may differ in terms of energy performance. Given this high complexity of improved energy efficiency in industry, there is a strong need for a systematic approach to manage industrial energy use.

One of the most promising means of reducing energy consumption and related energy costs is implementing an energy management in an organization. Research in relation to energy management has been conducted in the area of energy audit practices (e.g. Shen et al., 2012), evaluation of energy audit programs (e.g. Fleiter et al., 2012b), energy system or process optimization by statistical modeling (e.g. Giacone \& Mancò, 2012), development and evaluation of energy end-use industrial policy programs and measures (e.g. Tanaka, 2011), as well as performing energy efficiency benchmarking (e.g. Saygin et al., 2011). A comprehensive review of published scientific articles on energy management practices in industry is currently lacking, calling for such a review to be conducted.

Thus, the aim of this paper is to conduct a systematic review of scientific publications in the area of industrial energy management. Based on that, we develop a conceptual framework of an energy management. The aim has been broken down into three research questions:

Research Question 1: What is the existing evidence base regarding operating an energy management in an industrial company?

Research Question 2: What conceptual elements and detailed activities need to be considered in an industrial company's energy management?

Research Question 3: Based on the above research questions, how can this knowledge be synthesized into an integrative conceptual framework of an energy management? 
The remainder of this paper is structured as follows: First, a brief overview of energy management as a support function in industrial companies is outlined. In this section we also highlight existing definitional shortcomings in the literature. Second, the methodology of the systematic review as applied in the paper will be described. Third, we present the review results, including a brief bibliographical analysis of the research field. Fourth, based on the synthesis of the review results, a comprehensive conceptual framework of a corporate energy management is developed. Finally, the results as well as the research implications are discussed at the end of the paper.

\section{Energy management as a support function in industrial companies}

Energy management as a support function in industrial companies has developed considerably within the last twenty years. Historically, energy as an input factor within the industrial production process had low or even zero priority for corporate management in industrial companies as energy costs were only a small part of total production costs since energy prices were low and relatively stable at that point of time. Therefore, energy costs were in most cases only treated as overhead rather than as a cost category for which managers were directly accountable for (Caffal, 1995). This situation has changed with the considerably rising energy sourcing prices in Europe within the last decade, exemplified by the development of electricity prices for industrial consumers in Germany which increased by more than $80 \%$ between 2000 and 2015 (German Federal Statistical Office, 2015). As a result, the number of organizations addressing energy-related issues has risen in recent years and increasing activity concerning energy management can be determined in business practice. Industrial companies have seemed to realize that energy management can be an effective lever for enhancing their production systems and operations towards improved energy efficiency and thereby reducing energy use and related energy costs. The ISO 50001 standard, released in June 2011 by the International Organization of Standardization (International Organization of Standardization, 2011), additionally enforces energy management activities of companies and other organizations globally as it provides practical guidance and specifies minimum requirements for implementing a formal energy management system. By May 2014, 7.346 company sites worldwide had already been certified according to the ISO 50001 standard (German Federal Environment Agency, 2014).

In spite of the increasing activity in regard to energy management in business practice, so far there is no consistent understanding of energy management in academic literature (Backlund et al., 2012). Table 1 provides a selection of different definitions of energy management and displays the existing diversity of interpretation. As a result, those definitions possess a different scope in regard to the strategic, operational or tactical level of a company, highlight dissimilar aspects of what composes energy management and aim for a diverse set of possible objectives. As one result of this paper, we will later elaborate our definition/understanding of an industrial energy management. 
Table 1: Selection of definitions of energy management in the literature

\begin{tabular}{|c|c|}
\hline Source & Definition \\
\hline $\begin{array}{l}\text { O'Callaghan \& Probert, 1977, } \\
\text { p. } 128\end{array}$ & $\begin{array}{l}\text { "Energy management applies to resources as well as to the supply, } \\
\text { conversion and utilization of energy. Essentially it involves } \\
\text { monitoring, measuring, recording, analyzing, critically examining, } \\
\text { controlling and redirecting energy and material flows through } \\
\text { systems so that least power is expended to achieve worthwhile aims." }\end{array}$ \\
\hline Kannan \& Boie, 2003, p. 946 & $\begin{array}{l}\text { "Energy management is the judicious and effective use of energy to } \\
\text { maximize profits and to enhance competitive positions through } \\
\text { organizational measures and optimization of energy efficiency in the } \\
\text { process." }\end{array}$ \\
\hline $\begin{array}{l}\text { Association of German } \\
\text { Engineers, 2007, p. } 3\end{array}$ & $\begin{array}{l}\text { "Energy management is the proactive, organized and systematic } \\
\text { coordination of procurement, conversion, distribution and use of } \\
\text { energy to meet the requirements, taking into account environmental } \\
\text { and economic objectives." }\end{array}$ \\
\hline Capehart et al., 2008, p. 1 & $\begin{array}{l}\text { "To us, energy management is: The efficient and effective use of } \\
\text { energy to maximize profits (minimize costs) and enhance } \\
\text { competitive positions." }\end{array}$ \\
\hline $\begin{array}{l}\text { German Energy Agency, } \\
2010 \text {, p. } 9\end{array}$ & $\begin{array}{l}\text { "Energy management is considered as the proactive and systematic } \\
\text { coordination of procurement, conversion, distribution and use of } \\
\text { energy within a company, aiming on continuously reducing energy } \\
\text { consumption and related energy costs." }\end{array}$ \\
\hline Abdel & $\begin{array}{l}\text { "Energy management is the strategy of meeting energy demand when } \\
\text { and where it is needed. This can be achieved by optimizing energy } \\
\text { using systems and procedures so as to reduce energy requirements } \\
\text { per unit of output while holding constant or reducing total costs of } \\
\text { producing the output from these systems." }\end{array}$ \\
\hline Bunse et al., 2011, p. 668 & $\begin{array}{l}\text { "In our research we define 'energy management in production' as } \\
\text { including control, monitoring, and improvement activities for energy } \\
\text { efficiency." }\end{array}$ \\
\hline $\begin{array}{l}\text { German Federal Environment } \\
\text { Agency, 2012, p. } 16\end{array}$ & $\begin{array}{l}\text { "Energy management comprises the total of planned and executed } \\
\text { actions in order to ensure a minimum of energy input for a } \\
\text { predefined performance." }\end{array}$ \\
\hline Ates \& Durakbasa, 2 & $\begin{array}{l}\text { "Energy management (EM) is considered a combination of energy } \\
\text { efficiency activities, techniques and management of related processes } \\
\text { which result in lower energy cost and } \mathrm{CO}_{2} \text { emissions." }\end{array}$ \\
\hline
\end{tabular}

In order to implement energy management within a company, a formal energy management system (EnMS) is a very supportive tool. An EnMS is a "set of interrelated or interacting elements to establish an energy policy and energy objectives, and processes and procedures to achieve those objectives" (International Organization of Standardization, 2011, p. 2). It encompasses the organizational and informational structures as well as the technical tools (e.g. hard- and software) needed to implement an energy management (Association of German Engineers, 2007).

Former articles have focused on defining elements as minimum requirements for establishing and operating energy management in general or an EnMS in particular (Abdelaziz et al., 2011; Ates \& Durakbasa, 2012; Christoffersen et al., 2006; McKane et al., 2007; Thollander \& Ottosson, 2010). Those elements are illustrated in Table 2, also distinguishing whether the elements are fully, partially or not considered within the analyzed articles. 
Table 2: Minimum requirements for establishing and operating an energy management

\begin{tabular}{|c|c|c|c|c|c|}
\hline $\begin{array}{c}\text { Minimum } \\
\text { Requirements }\end{array}$ & $\begin{array}{l}\text { Christoffersen } \\
\text { et al., } \\
2006\end{array}$ & $\begin{array}{l}\text { McKane } \\
\text { et al., } \\
2007\end{array}$ & $\begin{array}{l}\text { Thollander } \\
\text { \& Ottosson, } \\
2010\end{array}$ & $\begin{array}{l}\text { Abdelaziz } \\
\text { et al., } \\
2011\end{array}$ & $\begin{array}{c}\text { Ates \& } \\
\text { Durakbasa, } \\
2012\end{array}$ \\
\hline $\begin{array}{l}\text { Develop and implement a } \\
\text { long-term strategic plan, } \\
\text { including an energy policy and } \\
\text { energy saving targets }\end{array}$ & 1 & 1 & & & 1 \\
\hline $\begin{array}{l}\text { Organize energy activities by } \\
\text { allocating responsibilities and } \\
\text { tasks }\end{array}$ & 1 & 0 & 0 & 1 & 0 \\
\hline $\begin{array}{l}\text { Establish a cross-divisional } \\
\text { management team led by an } \\
\text { energy coordinator (also } \\
\text { called energy manager) who } \\
\text { reports directly } \\
\text { management }\end{array}$ & 0 & 0 & 0 & 0 & 1 \\
\hline $\begin{array}{l}\text { Develop relevant policies and } \\
\text { procedures, e.g. regarding } \\
\text { energy procurement, energy } \\
\text { use or energy-efficient } \\
\text { purchases etc. }\end{array}$ & 1 & 0 & 0 & 0 & 1 \\
\hline $\begin{array}{l}\text { Conduct an (initial) energy } \\
\text { audit to identify energy-saving } \\
\text { potentials }\end{array}$ & 0 & $\bigcirc$ & & 0 & 0 \\
\hline $\begin{array}{l}\text { Plan and implement specific } \\
\text { energy-saving projects (also } \\
\text { called energy efficiency } \\
\text { measures) }\end{array}$ & 8 & & & 1 & \\
\hline $\begin{array}{l}\text { Identify key performance } \\
\text { indicators, unique to the } \\
\text { company, that are tracked } \\
\text { regularly to measure progress }\end{array}$ & 0 & 0 & 0 & $\bigcirc$ & 0 \\
\hline $\begin{array}{l}\text { Meter and monitor the energy } \\
\text { consumption of main } \\
\text { production processes on a } \\
\text { regular basis }\end{array}$ & 0 & 0 & 0 & 1 & 1 \\
\hline $\begin{array}{l}\text { Report progress periodically } \\
\text { to management }\end{array}$ & 0 & 0 & 0 & 0 & 0 \\
\hline 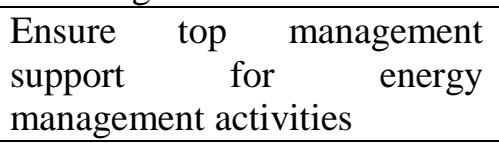 & 0 & 0 & 0 & 0 & 0 \\
\hline $\begin{array}{l}\text { Seek to actively involve the } \\
\text { employees in energy } \\
\text { management by informing, } \\
\text { motivating and educating } \\
\text { them }\end{array}$ & 1 & 0 & 1 & 1 & 1 \\
\hline
\end{tabular}

\section{Legend: Fully considered 1 Partially considered $\bigcirc$ Not considered}

Analyzing the results displayed in Table 2, it becomes apparent that the sets of minimum requirements explicated in the articles differ in the number of elements as well as in the composition of the individual elements. Furthermore, it remains unclear whether the list of minimum requirements is 
conclusive or not and whether it is suitable to describe a fully developed energy management. At this point it has therefore to be concluded that so far there is no comprehensive conceptual framework of energy management existent in the academic literature. We respond to this research gap by performing a systematic review of academic journal publications in the area of energy management in industry and use its results to develop a comprehensive conceptual framework of an energy management. The methodological approach of the systematic review is outlined in the next chapter.

\section{Method}

In this paper we conduct a systematic review, a rigorous review methodology originally developed mainly within medical research and first outlined for the field of management and organization studies by Tranfield et al. (2003). The aim of such a systematic review is to locate relevant existing studies based on a prior formulated research question, to evaluate and synthesize their respective contributions and to report the evidence in a way that clear conclusions with regard to further research and managerial practice can be drawn (Denyer \& Tranfield, 2009).

Systematic reviews exhibit significant advantages compared to traditional narrative approaches of literature reviews. Those traditional reviews generally do not follow a formal methodology, thus resulting in lacking transparency and replicability by others. Researchers can focus on "preferred" literature sources and base their review on a personal, purposive selection of materials they believe to be important. Systematic reviews help to reduce those implicit researcher biases (Denyer \& Tranfield, 2009). Through the adoption of search strategies, predefined search strings as well as inclusion/exclusion criteria, systematic reviews effectively force researchers to search for all relevant studies beyond their own horizon of experience. Furthermore, the application and extensive documentation of a clear review protocol improves the methodological transparency of the review and enables future replication by other researchers.

As the motivation and research questions of the review have already been outlined in the introduction, the remainder of this section will focus on how the review was conducted and describe in detail the search strategy, selection criteria and synthesis criteria applied in this paper.

Our search strategy consisted of looking for relevant studies within scientific literature sources, represented by academic studies published in peer-reviewed journals. We searched online databases to identify all articles published on the topics of industrial energy management and energy efficiency enhancement between 1979 and 2014. We have chosen 1979 as a starting point for our review, as it was in this year that the second global oil crisis occurred due to decreased oil output in the wake of the Iranian Revolution. This event marks a turning point regarding the global awareness of energy demand and thereby sets a starting point for energy management activities in industry. The major sources of information used to identify the studies eligible for this review were the scholarly databases Web of Science, EBSCO (including Business Source Complete and EconLit) and ScienceDirect, which identify relevant academic articles published in the domains of management and business administration (here specifically: strategic management, accounting and finance, operations management, management of information systems and human resource management) as well as engineering - domains in which articles on the topic of interest have appeared. We used two different search strings which comprised "energy management", "industry" or "energy efficiency" as keywords to identify scientific articles: 
Search String 1: "energy management" (TITLE) AND "industry" (TOPIC, ABSTRACT, TITLE/ABSTRACT/KEYWORDS) AND YEAR > 1978 AND DOCUMENT TYPE $=($ PEERREVIEWED JOURNAL) ARTICLE*

Search String 2: "energy efficiency" (TITLE) AND ("industry" (TOPIC, TITLE/ABSTRACT/ KEYWORDS) OR "management" (TOPIC, ABSTRACT, TITLE/ABSTRACT/KEYWORDS)) AND YEAR $>1978$ AND DOCUMENT TYPE $=($ PEER REVIEWED JOURNAL $)$ ARTICLE*

* The search strings differed slightly depending on the functionality of the database used.

To ensure complete coverage, in a later step of the process, we also identified additional academic studies through manual screening of cross-referencing. Books, contributions to edited volumes, conference papers, periodicals, and working papers were not included in our review, as such research usually goes through a less rigorous peer-review process, and they are less readily available (Podsakoff et al., 2005). The entire process of our search is illustrated in Figure 1. Finally, 44 scientific articles were considered to be eligible for our systematic review.

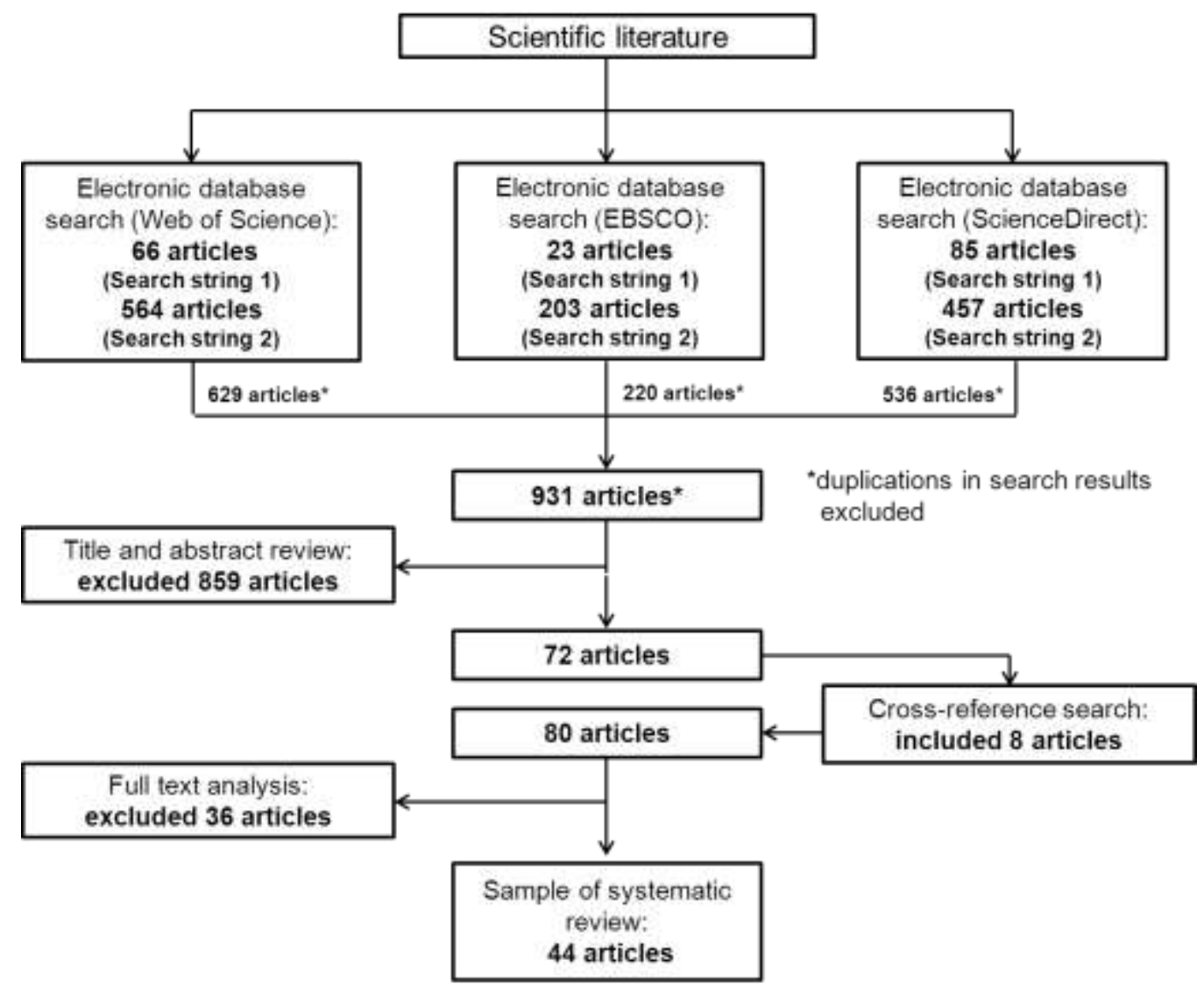

Figure 1: Mapping the scientific literature search

Our criteria for determining which studies need to be considered from the scientific literature are detailed in Table 3. Besides the general criteria language, full-text availability, research discipline, sector and date of publication, the decision on the relevance with regard to the content of the article was particularly essential. We have focused exclusively here on energy management in industry on an organizational level of analysis, while we have declared research on energy management on a micro level (e.g. energy management for buildings/facilities/sites or even system-/process-related) as well as on a macro level (e.g. industry, regional or state level) beyond our scope. 
We also have excluded articles which only focus on antecedents in the form of barriers and driving forces of energy management as well as articles which address policy issues rather than management issues. The reason for this was that research on barriers and drivers normally only studies the investment decision as the analyzing variable (Thollander \& Palm, 2012) and policy issues especially focus on external drivers for energy efficiency.

Table 3: Selection criteria of the systematic review

\begin{tabular}{|c|c|c|}
\hline Criterion & Inclusion & Exclusion \\
\hline Publication Type & Peer-reviewed academic journal & $\begin{array}{l}\text { Any other publication type (e.g. } \\
\text { books, contributions to edited } \\
\text { volumes, conference papers, } \\
\text { periodicals, working papers) }\end{array}$ \\
\hline Language & English & Any other language \\
\hline Availability & Available online as full text & $\begin{array}{l}\text { Not available online as full text* } \\
\text { *Remark: This was sometimes the case for } \\
\text { older articles. We did not use a document } \\
\text { delivery service to receive scanned copies of } \\
\text { those articles. }\end{array}$ \\
\hline Research discipline & $\begin{array}{l}\text { Management/Business Administration } \\
\text { or Engineering }\end{array}$ & Any other research discipline \\
\hline Time period & $\begin{array}{l}1979 \text { to August } 2014 * \\
\text { *Remark: The search was initially performed in } \\
\text { February 2014 and finally checked/ } \\
\text { complemented in August } 2014 .\end{array}$ & Any study published before 1979 \\
\hline Sector & Manufacturing industry & $\begin{array}{l}\text { Any other sector (e.g. service or } \\
\text { construction industry) }\end{array}$ \\
\hline Relevance & $\begin{array}{l}\text { - Article addresses (at least partly) } \\
\text { energy management in general, } \\
\text { associated practices or energy } \\
\text { efficiency measures on an } \\
\text { organizational level of analysis }\end{array}$ & $\begin{array}{l}\text { - Article addresses energy } \\
\text { management in general, } \\
\text { associated practices or energy } \\
\text { efficiency measures only on } \\
\text { micro or macro level of analysis } \\
\text { - Article focuses only on barriers } \\
\text { and driving forces of an energy } \\
\text { management } \\
\text { - Article addresses only govern- } \\
\text { mental policy issues rather than } \\
\text { management issues }\end{array}$ \\
\hline
\end{tabular}

After identifying the relevant articles, a data extraction form was constructed and data was extracted into a Microsoft Excel worksheet. Articles were coded according to bibliographic characteristics of the source, type of study, and contextual dimensions like geographical focus, company size and industry sector focus (see complete list of articles in the Appendix). Each of these categories is developed further in the descriptive analysis of the results section.

In order to synthesize the evidence base of the articles reviewed, we read all the articles fully and used an inductive procedure to analyze the papers. We have applied the constant comparison technique (Glaser \& Strauss, 1967) to identify important concepts and themes within the literature. The individual articles were coded for content and then analyzed in relation to one another, enabling us to detect higher-order themes within the literature (Strauss \& Corbin, 1990). Finally, we gathered similar themes into overarching dimensions that make up the basis of an emergent framework. The final data categorization with the aggregated dimensions strategy/planning, implementation/operation, 
controlling, organization, and culture is illustrated in Figure 2, which forms the basis for the following results section.

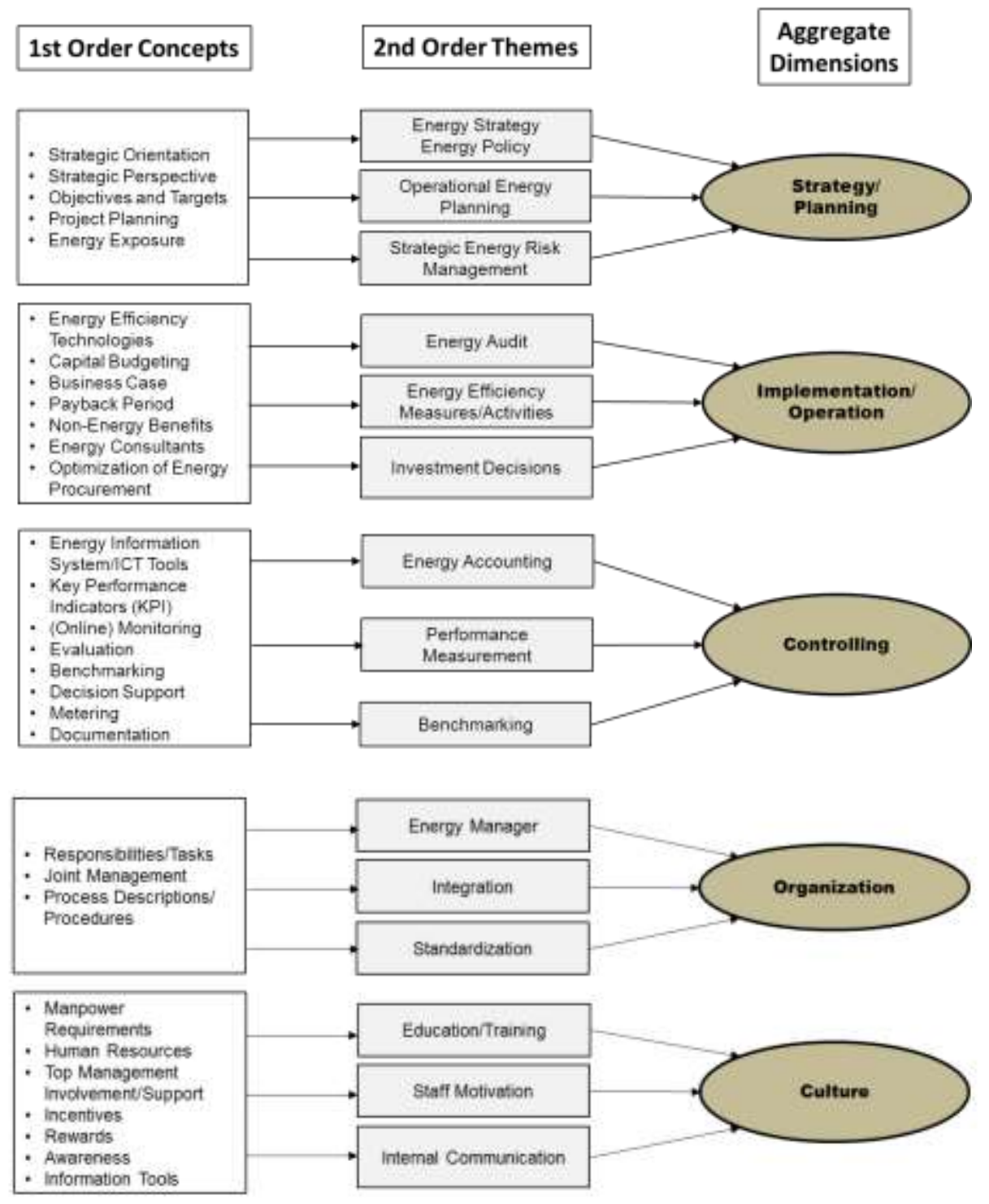

Figure 2: Structuring the content of the reviewed articles

\section{Results}

\subsection{Descriptive analysis}

\section{Journals and Year of Publication}

We analyzed the previously identified body of literature bibliographically and found the literature to be disjointed and widely distributed. Table 4 displays the evolutionary development of the field. Only four studies of the 44 articles identified in total appeared between 1979 and 1999. Between 2000 and 2014, research in the area of industrial energy management and energy efficiency enhancement gained momentum, with 40 additional articles published. Within the analyzed time period, most of the articles were published in 2013 (11 in total), which illustrates the current relevance of the topic. The majority 
of the articles appeared in the Journal of Cleaner Production (nine articles), followed by Energy (seven articles), Energy Policy (five articles), Energy Efficiency (three articles), Energy Conversion and Management (three articles) and Applied Energy as well as Renewable and Sustainable Energy Reviews (two articles each). Thirteen journals provided only one relevant article each and are aggregated in the column "Others" of Table 4.

Table 4: Summary of relevant articles by source and year

\begin{tabular}{|c|c|c|c|c|c|c|c|c|c|}
\hline Year & $\begin{array}{l}\text { Journal of } \\
\text { Cleaner } \\
\text { Production }\end{array}$ & Energy & $\begin{array}{l}\text { Energy } \\
\text { Policy }\end{array}$ & $\begin{array}{c}\text { Energy } \\
\text { Efficiency }\end{array}$ & $\begin{array}{c}\text { Energy } \\
\text { Conversion } \\
\text { and } \\
\text { Management }\end{array}$ & $\begin{array}{l}\text { Applied } \\
\text { Energy }\end{array}$ & $\begin{array}{c}\text { Renewable } \\
\text { and } \\
\text { Sustainable } \\
\text { Energy } \\
\text { Reviews }\end{array}$ & Others & SUM \\
\hline 1979 & - & - & - & - & - & - & - & 1 & 1 \\
\hline 1980 & - & - & - & - & - & - & - & - & 0 \\
\hline 1981 & - & - & - & - & - & - & - & - & 0 \\
\hline 1982 & - & - & - & - & - & - & - & - & 0 \\
\hline 1983 & - & - & - & - & - & - & - & - & 0 \\
\hline 1984 & - & - & - & - & - & - & - & 1 & 1 \\
\hline 1985 & - & - & - & - & - & - & - & 1 & 1 \\
\hline 1986 & - & - & - & - & - & - & - & - & 0 \\
\hline 1987 & - & - & - & - & - & - & - & - & 0 \\
\hline 1988 & - & - & - & - & - & - & - & - & 0 \\
\hline 1989 & - & - & - & - & - & - & - & - & 0 \\
\hline 1990 & - & - & - & - & - & - & - & - & 0 \\
\hline 1991 & - & - & 1 & - & - & - & - & - & 1 \\
\hline 1992 & - & - & - & - & - & - & - & - & 0 \\
\hline 1993 & - & - & - & - & - & - & - & - & 0 \\
\hline 1994 & - & - & - & - & - & - & - & - & 0 \\
\hline 1995 & - & - & - & - & - & - & - & - & 0 \\
\hline 1996 & - & - & - & - & - & - & - & - & 0 \\
\hline 1997 & - & - & - & - & - & - & - & - & 0 \\
\hline 1998 & - & - & - & - & - & - & - & - & 0 \\
\hline 1999 & - & - & - & - & - & - & - & - & 0 \\
\hline 2000 & 1 & - & - & - & - & - & - & 1 & 2 \\
\hline 2001 & - & - & - & - & - & - & - & - & 0 \\
\hline 2002 & - & - & - & - & - & - & - & - & 0 \\
\hline 2003 & - & 1 & 1 & - & 1 & - & - & - & 3 \\
\hline 2004 & - & - & - & - & - & - & - & 1 & 1 \\
\hline 2005 & - & - & - & - & - & - & - & - & 0 \\
\hline 2006 & 1 & - & - & - & - & - & - & 1 & 2 \\
\hline 2007 & - & - & - & - & 1 & - & - & - & 1 \\
\hline 2008 & - & 1 & - & 1 & - & - & - & - & 2 \\
\hline 2009 & - & - & - & - & - & - & - & 1 & 1 \\
\hline 2010 & 1 & 1 & 1 & - & 1 & - & - & 1 & 5 \\
\hline 2011 & 1 & - & - & - & - & - & 1 & - & 2 \\
\hline 2012 & 1 & 2 & 1 & 1 & - & - & 1 & 1 & 7 \\
\hline 2013 & 4 & 1 & 1 & - & - & 1 & - & 4 & 11 \\
\hline 2014 & - & 1 & - & 1 & - & 1 & - & - & 3 \\
\hline SUM & 9 & 7 & 5 & 3 & 3 & 2 & 2 & 13 & 44 \\
\hline
\end{tabular}

\section{Study Methodologies}

As Figure 3 shows, the preferred methodology within the analyzed studies was qualitative, either based on interviews or a case study design (17 articles). The second largest proportion of studies had a conceptual or theoretical design (11 articles), followed by the group of articles which applied a quantitative research methodology (nine articles), mostly using a survey design. Mixed method approaches (four articles), which combine qualitative and quantitative research methods, and literature 
reviews (three articles), investigating different sets and scopes of research questions, only played a minor role in the literature.

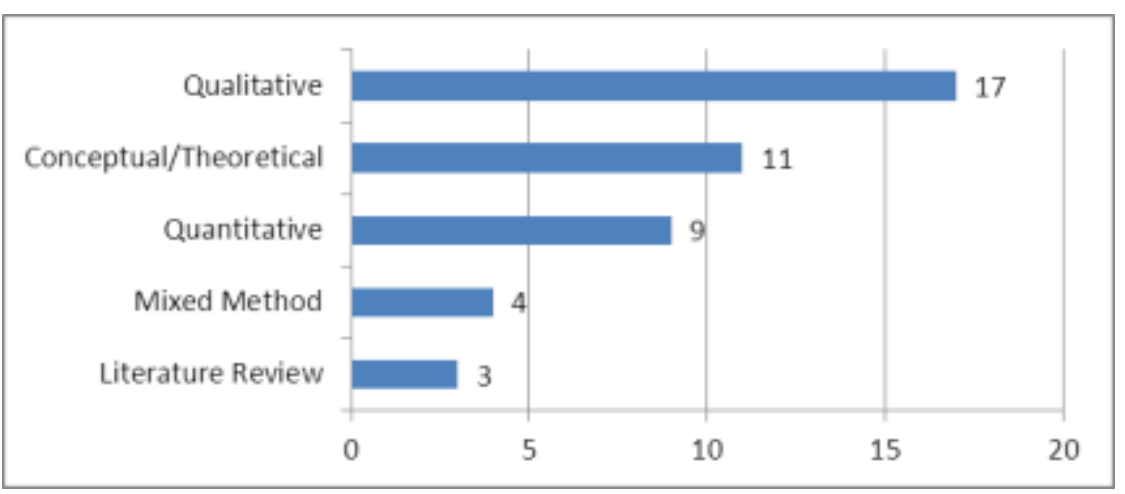

Figure 3: Study Methodologies (number of articles; $n=44$ )

\section{Geographical Focus}

Figure 4 illustrates the geographical distribution of the analyzed studies. The distribution shows global interest in the topic, though the majority of studies had a single-country focus on a developed economy. The countries on which most of the articles focused were China, Germany, Sweden and the United States (four articles each). Only four studies applied a multiple country focus, ranging from cross-country case studies (e.g. Bunse et al., 2011) to surveys across continents (e.g. Alcorta et al., 2014). A large proportion of the analyzed studies did not specify a geographical focus (ten articles). Those studies exclusively follow a general conceptual/theoretical design or represent literature reviews. While for those two types of studies the geographical focus is of minor importance, it represents a fundamental contextual factor for the empirical studies.

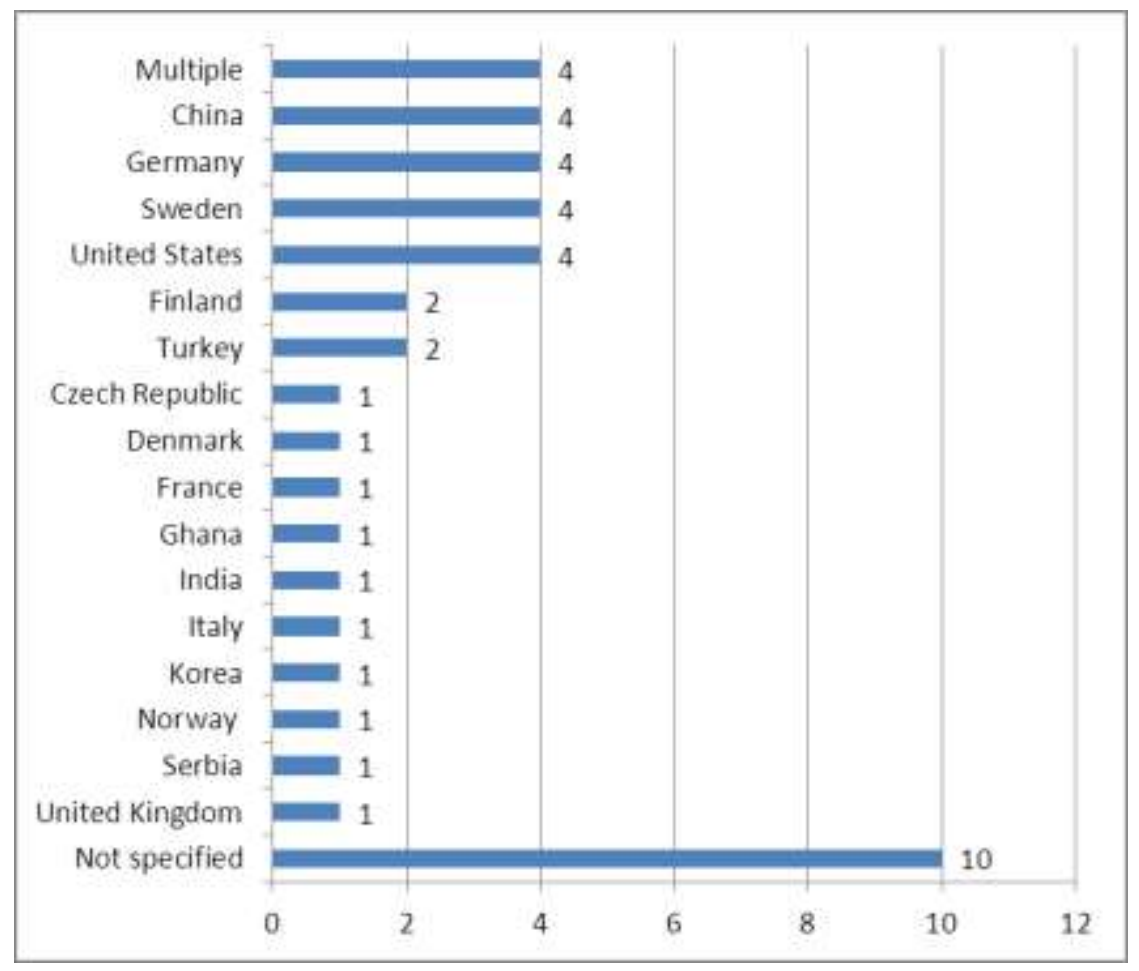

Figure 4: Geographical focus of studies (number of articles; $n=44$ ) 


\section{Company Size Focus}

Figure 5 illustrates the company size distribution of the analyzed studies. The largest proportion of the analyzed studies did not specify company size at all ( 25 articles), followed by mixed-size studies (seven articles), which consider a range of different company sizes. An equal number of studies indicate a focus on large companies and on small and medium-sized companies (six articles each). Differences between those two groups become apparent however when combining the company size focus with the chosen research methodology: all studies which focus on large companies chose a qualitative study design (e.g. Gordić et al., 2010; Virtanen et al., 2013), whereas the studies which focus on SME mainly applied a quantitative or mixed method design (e.g. Önüt \& Soner, 2007; Blass et al., 2014).

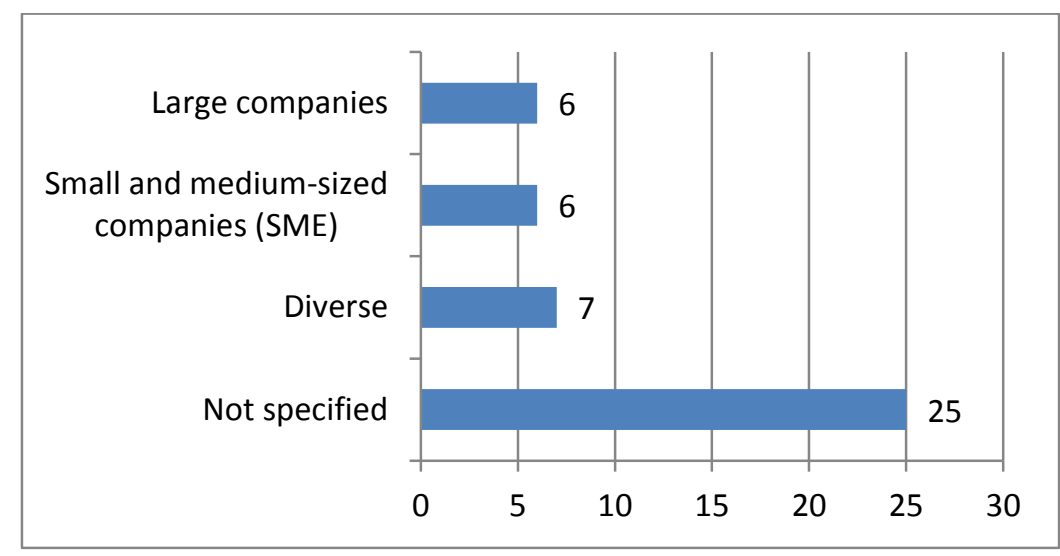

Figure 5: Company size focus of studies (number of articles; $n=44$ )

\section{Industry Sector Focus}

Figure 6 illustrates the industry sector distribution of the analyzed studies. The largest proportion of the analyzed studies represents mixed-industrial studies which include a wide range of different industry sectors (19 articles). Single-sector studies mainly focus on the chemical industry (three articles), the food processing industry, the iron and steel industry or the pulp and paper industry (two articles each). These in particular represent high energy-intensity sectors within the manufacturing industry, where a high potential for a reduction of energy use as well as related energy costs is located.

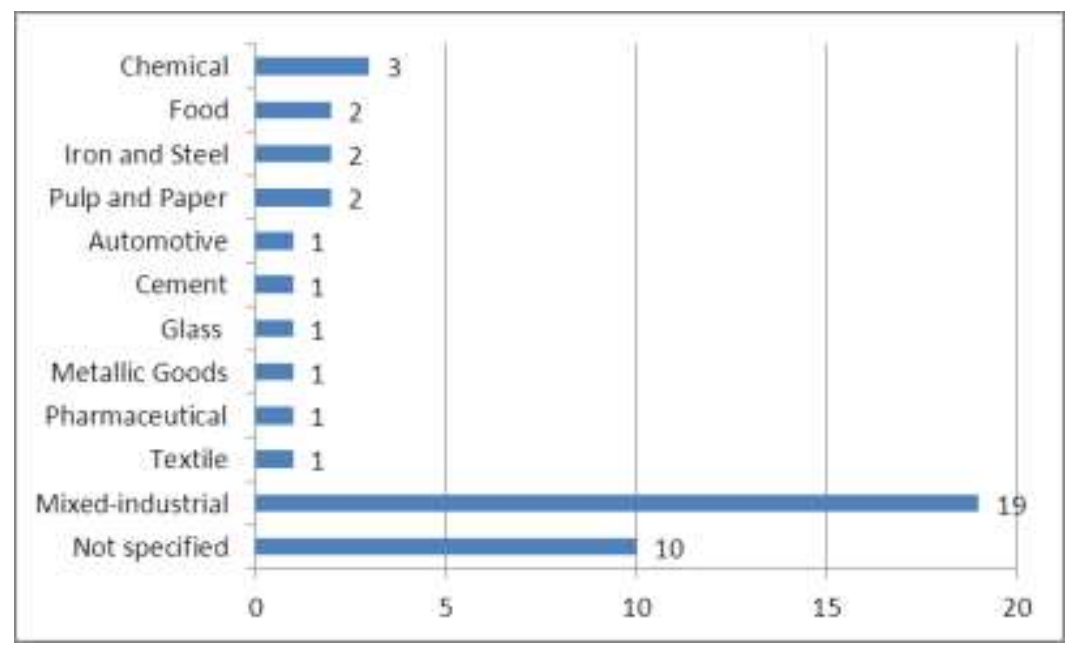

Figure 6: Industry sector focus of studies (number of articles; $n=44$ ) 


\section{Research Focus}

Figure 7 illustrates the distribution regarding the research focus of the analyzed studies. We hereby applied the previously developed, content-related overarching categories. The largest proportion of the analyzed studies addressed aspects related to the implementation/operation of an energy management (22 articles), followed by studies which addressed aspects related to controlling aiming at energy efficiency improvement and energy cost reduction (14 articles). A considerable lower proportion of studies focused on cultural aspects (nine articles) or on strategic and planning aspects (seven articles). The minority of studies picked up organizational aspects of an energy management (six articles).

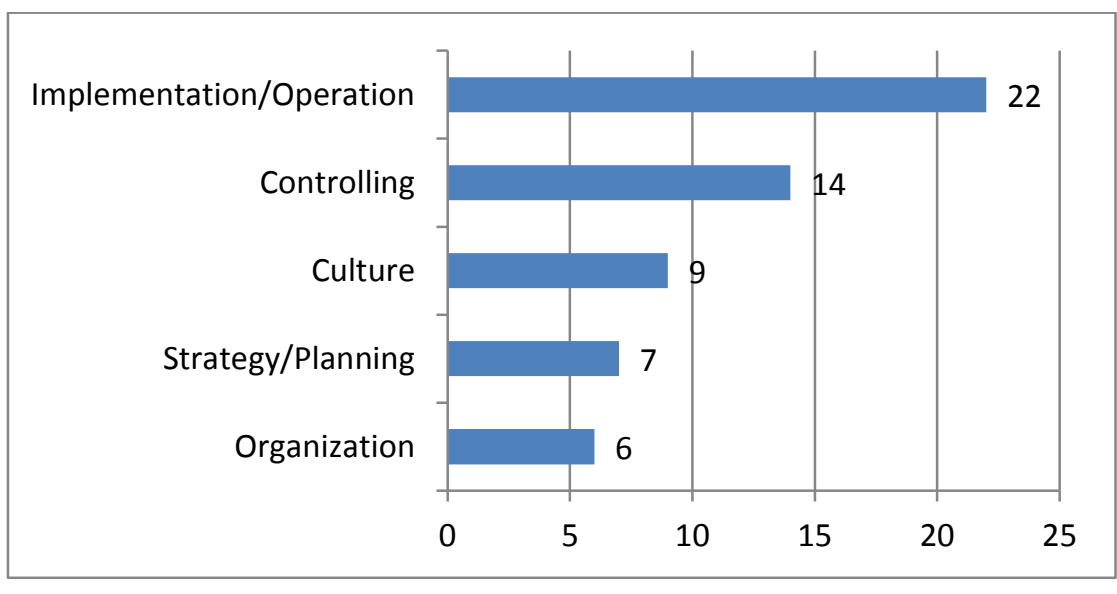

Figure 7: Research focus of studies (number of articles; $n=44$; multiple selection possible)

In the following sections, we proceed by synthesizing the current state of the research in a systematic way. For this purpose, we use the categorization as already outlined in the method section of this paper, comprising the aggregated dimensions strategy/planning, implementation/operation, controlling, organization, and culture.

\subsection{Strategy/Planning}

Three main themes are prevalent in the studies analyzing energy management from a strategic and planning perspective. These are the need for a written long-term energy strategy/energy policy, energy planning and the related target-setting process on a company level, and finally the need for a systematic strategic risk management approach to minimize the exposure of companies related to their energy use.

Several papers have analyzed the current state of energy management regarding the existence of a written long-term energy strategy/energy policy. Lambert and Stock (1979) were the first authors to emphasize the importance of a written energy policy as an outcome of a company's strategic planning process. In their cross-sectional study they explored the attitudes of 224 U.S. business executives on the role of an energy policy, covering a wide range of different industry sectors. At that point in time, only one-third of the companies surveyed indicated that they had a formal written energy policy. Interestingly, comparable findings regarding the existence of an energy strategy in companies were obtained later in other empirical studies as well. Thollander and Ottosson (2010) analyzed the existence and duration of a long-term energy strategy within the Swedish pulp and paper and foundry industries. Finally, about one-fifth of the studied Swedish pulp and paper mills as well as more than 
half of the foundries lacked such a long-term energy strategy. Moreover, less than half of the studied pulp and paper mills and less than $30 \%$ of the studied foundries had developed a long-term energy strategy which covered a time period of five years and more. The results revealed that most of the surveyed companies either lacked a strategy or developed an energy strategy only focusing on the short-term. These results clearly indicated that energy at that point in time was not a highly prioritized strategic issue, which is definitely surprising when taking into account the energy-intensive context of those industries. Ates and Durakbasa (2012), in their study of energy management practices in energyintensive industries in Turkey, also highlight the importance of a formal (written) energy strategy/energy policy. Nevertheless, only $40 \%$ of the surveyed Turkish companies indicated that they had already developed a formal energy policy. Many other companies stated that they communicate energy-related goals and principles only verbally. A study by Rudberg et al. (2013) additionally illustrates that energy is not treated strategically even in energy-intensive companies. They identified in their single-case study of a Swedish chemical company several obstacles that hinder energy being treated strategically, for example poor organizational integration of energy management or the perception that energy is not "core" for the business due to a relatively small share of energy costs within total costs. Rudberg et al. (2013) argue that the main prerequisites for establishing a strategic perspective on a company's energy system are political continuity regarding energy issues as an external factor and the establishment of an energy manager who has the main responsibility for the energy management in a company as well as the possibility to integrate energy planning and initiate energy-saving activities corporate-wide as an internal factor.

Regarding the energy planning and related target-setting process on a firm level, Rietbergen and Blok (2010) provide a taxonomy of targets for industrial energy use or greenhouse gas emission reduction. They argue for the use of SMART targets within energy planning which meet the requirements to be specific, measurable, appropriate, realistic and timed. Furthermore they distinguish different target coverages (energy consumption, $\mathrm{CO}_{2}$ emissions or (all) greenhouse gas (GHG) emissions) as well as different categories of quantitative targets, comprising volume targets (e.g. reduction of total energy use by $30 \%$ by 2020 compared to the level in 1990), physical efficiency targets (e.g. the specific energy use should reach a level of $30 \mathrm{GJ} /$ tonne of product in 2020), economic intensity targets (e.g. the energy intensity should reach a level of $1,000 \mathrm{kWh} / \$$ sales by the year 2020) and economic targets (e.g. all energy efficiency improvement measures with a payback period of less than five years should be implemented). Depending on the specific goals that a company wants to achieve, different target categories need to be considered within the energy planning. The use of energy-related targets also was analyzed in an empirical study by Martin et al. (2012). Based on interviews with managers of 190 manufacturing firms in the UK, they revealed that roughly two-thirds (125) of the firms within the sample developed targets for energy consumption (17 of which were expenditure targets, while the others were volume targets).

As a final strategic component of energy management, Vasudevan and Higgins (2004) argue for a strategic energy risk management (SERM). They define SERM as a systematic approach to analyze the exposure of companies to various components of risk related to their energy use and manage it in the context of the company's predetermined financial objectives and risk tolerances (Vasudevan \& Higgins, 2004). In their view, most corporate bottom lines would benefit, whereas the utmost importance exists in industries that are particularly sensitive to energy price volatility as well as energy supply shortages such as energy-intensive process industries. 


\subsection{Implementation/Operation}

Three themes are prevalent in the studies analyzing energy management from an implementation and operations perspective. These are aspects regarding the implementation of energy efficiency measures, the investment decision on energy efficiency measures and energy auditing.

Several papers address aspects of how energy efficiency in production companies can be improved. This subject area is clearly dominated by a technical perspective. One typical example in this regard is Abdelaziz et al. (2011), who in their literature review specify a comprehensive overview on various energy-saving technologies and technical measures (e.g. high-efficiency motors, waste heat recovery, air compressor leak prevention). Another good example are Hasanbeigi and Price (2012) who, based on a case study review of various textile plants around the world, provide an overview of 184 different energy efficiency technologies and technical measures applicable to the textile industry. Kannan and Boie (2003), in a case study of a German bakery, also described various technical measures for saving energy, such as installing a new electric bake oven, new lighting equipment, optimized hot water usage, insulation of pipes and recalibration of thermostats. Zhang and Wang (2008), in their empirical study based on 90 Chinese iron and steel enterprises, provide statistical evidence that some productive efficiency growth can be attributed to the adoption and amelioration of two specific energy-saving measures (pulverized coal injection technology, PCI, and continuous casting technology, CCT). Stenqvist and Nilsson (2012) present results from an impact evaluation of a Swedish five-year industrial energy efficiency policy program. They compiled an overview of various technical as well as operation and maintenance (O\&M) measures and their outcome on electricity savings which the companies reported to the Swedish Energy Agency. The measures were subdivided into different types of end-use technologies: motors and motor-related processes, pumping systems, compressed air systems, fan systems, heating and ventilation, cooling systems and lighting systems. Lastly, Mills et al. (2008) present several technical opportunities for reducing energy costs within high-tech industries.

Many other papers focus on how the current status quo regarding the implementation of energy efficiency measures can be described. Christoffersen et al. (2006), based on the results of a telephone survey covering 304 Danish industrial firms, identify $65 \%$ of the surveyed companies which regularly implement specific energy-saving projects. Liu et al. (2012) also observed a high performance regarding energy-saving activities (ESA). In their empirical study based on 125 small and mediumsized companies in the region of Taicang, China, nearly all of the 15 included ESA achieved implementation rates in the surveyed companies of more than 50\%. In a similar study in Korea, Suk et al. (2013) showed that eight out of 15 included ESA still obtain implementation rates of more than $50 \%$. Nevertheless, there are also studies which generate contrary results in other regional contexts. For example, Pons et al. (2013) in their empirical study based on a Spanish and Slovenian subsample of the European Manufacturing Survey obtained relatively low implementation rates of various energy-saving technologies, varying between $8 \%$ and $56 \%$. In a case study of the largest industrial park in Ghana, Apeaning and Thollander (2013) empirically investigated to what extent various energy-efficient technologies and measures were adopted by the surveyed companies. They identified that technologies to reduce electricity consumption in particular have the highest adoption rate, followed by technologies to ensure energy-efficient lighting. Nevertheless, the results of this study clearly indicated that in summary energy was poorly managed in the surveyed companies with a relatively low adoption rate of available energy efficiency technologies.

Findings on low adoption rates are picked up by Fleiter et al. (2012). They argue that the consideration of the specific characteristics of energy efficiency measures (EEM) can enhance the understanding of their adoption. For this purpose, they suggest a classification scheme for EEMs in industry which 
includes 12 characteristics based on the relative advantage, technical and information context of the EEM. Trianni et al. (2014) draw upon this first classification scheme and on their part develop another suggestion to classify EEMs based on 17 attributes grouped according to six categories: economic, energy, environmental, production-related, implementation-related and possible interaction with other systems. Both frameworks provide a comprehensive view of EEMs, presenting the most relevant perspectives for industrial decision-makers and thereby improving the decision-making process within an energy management.

Several other papers relate to the investment decision on energy efficiency measures. Gruber and Brand (1991) observed in an empirical study covering 500 small and medium-sized German companies from a total of eight different industries that less than $50 \%$ of the surveyed firms conduct a systematic economic calculation to determine the return on investment (ROI). The average required payback period for those companies that perform investment calculations was at that point of time about four years. Thollander and Ottosson (2010) within their empirical study of the Swedish pulp and paper and foundry industries also analyzed the criteria for payback periods. The results show that most of the surveyed companies apply a pay-off criterion of three years or less for energy efficiency investments. Alcorta et al. (2014) explored energy efficiency investments derived from survey work in developing countries in 119 projects across nine manufacturing subsectors. They found a generally very high level of internal rates of return at project level with payback periods ranging from 0.9 to 2.9 years but note that these metrics do not always appropriately influence corporate decision-making for a number of different reasons. In this regard, Sandberg and Söderström (2003) investigated the need from a managerial perspective to improve the decision support for energy efficiency investments. They identified that the improvement of working methods and corresponding tools, the access to correct information to decrease uncertainty and associated risks, better follow-up activities as well as transparent and understandable calculations are the predominant factors in improving those investment decisions. Aflaki et al. (2013) also highlight the issue that in practice many profitable energy efficiency projects that theoretically could be implemented in industrial companies in the end are not. The reason for this is often a lack of organizational know-how to identify, value and execute these projects. Aflaki et al. (2013) in their exploratory case study of a German facility of a pharmaceutical company identified four factors essential for the successful implementation of energy efficiency projects in a company: reliable measurement to understand the energy consumption baseline, a management system to ensure clear responsibilities, tested and reliable technologies, and lastly financial and technical expertise that provides the necessary competence for project evaluation and implementation.

Pye and McKane (2000) argue for a modified approach for investment calculations and present case studies including both energy and non-energy benefits (NEB) such as waste reduction and pollution prevention. In their view, the non-energy benefits of energy efficiency projects often exceed the value of energy savings, so energy savings should be viewed more correctly as part of the total benefits, rather than the focus of the investment calculations. Quantifying the total benefits of energy efficiency projects helps companies understand the financial opportunities of investments in energy-efficient technologies. Worrell et al. (2003) also propose modifying investment calculations for energy efficiency measures by including productivity benefits, one specific type of NEB, in the economic assessment. Their review of 70 industrial case studies from widely available published databases suggests that energy efficiency investments can provide a significant boost to overall productivity within industry. Jackson (2010) studies current capital budgeting practices of companies and their impact on energy efficiency investments. He argues that the prevalent use of short payback requirements biases investment choices towards "sure bet" investments and bypasses many profitable 
efficiency investment options. Jackson (2010) therefore describes the financial industry management tool Value-at-Risk (VaR) and extends it to an Energy-Budgets-at-Risk application (EBaR) to enable more accurate energy efficiency investment decisions.

Lastly, energy audits are highlighted as an important measure within the operation of an energy management of a company to constantly review the status quo and identify energy saving potential. Abdelaziz et al. (2011) describe three different types of energy audits: preliminary audits, general audits and detailed audits. A preliminary audit (alternatively also called simple audit or walk-through audit) is the simplest and quickest type of audit. It only involves minimal interviews with siteoperating personnel, a brief review of facility utility bills and other operating data, and a walk-through within the facility. The general audit expands the preliminary audit by collecting more detailed information about facility operation, e.g. by additional metering of specific energy-consuming machines or systems. Last but not least the detailed audit again expands the general audit by providing a dynamic model of energy-use characteristics of the existing facility which for example allows the identification of load profile variations on a short and longer term basis. Two practical examples of an energy audit and its detailed outcomes are described by Kannan and Boie (2003) in a case study of a German bakery resulting in a reduction of $6.5 \%$ of total energy consumption and by Gordić et al. (2010) in a case study of a Serbian car manufacturer which achieved an approximate $25 \%$ reduction of total energy consumption.

\subsection{Controlling}

Three themes are prevalent in the studies analyzing energy management from a performance management perspective. These are aspects regarding energy accounting, performance measurement and benchmarking.

Several papers address aspects of energy accounting within companies. Bunse et al. (2011) for example highlight that energy efficiency monitoring and constant analysis of the energy consumption of manufacturing and support processes are an important basis for energy management as it enables decision makers to identify improvement opportunities and to keep track of the effects of their decisions on energy use. Moreover, monitoring of the company's energy consumption supports the judgment of whether anticipated energy savings could be achieved or not (Kannan \& Boie, 2003). In this regard, Bunse et al. (2011) also emphasize the role of information and communication technologies (ICT) as enablers for energy-efficient manufacturing. ICT may effectively support the control of production processes as well as the evaluation and assessment of potential energy-saving investments. Thollander and Ottosson (2010) within their empirical study of the Swedish pulp and paper and foundry industries also analyzed the internal allocation of energy costs. They emphasize that in many organizations and in particular those with multiple departments and divisions, inadequate allocation of energy costs may decelerate energy management efforts (Rohdin \& Thollander, 2006). The results show that about one-fifth of the studied mills and about one-third of the studied foundries do not allocate energy costs at all, and that about one-tenth of the studied industries energy costs are allocated ineffectively per square meter and per number of employees. Thollander and Ottosson (2010) suggest a monitoring system using sub-metering at facility level for a proper energy cost allocation.

Other papers address aspects regarding concepts and approaches for performance measurement as an integral part of an energy management. One important factor in this regard is the definition and application of appropriate key performance indicators (KPI) for energy efficiency. Usually those 
indicators are ratios describing the relationship between an activity (e.g. a production process or its physical outcome) and the required energy (Bunse et al., 2011). Due to the variety of industrial processes and their complexity, there are a multitude of different possible energy efficiency indicators. Bunse et al. (2011) provide a helpful overview of the various energy efficiency indicators (economic, physical, thermodynamic and hybrid indicators) and their applications. They also argue that adequate KPI for energy efficiency should be defined on company, plant and if necessary even on process level. Sivill et al. (2013) analyzed the development needs of energy performance measurement based on an empirical study where interviews were conducted with managers and operators in three energyintensive industrial sectors in Finland. They concluded that the data and indicators available today do not allow for effective performance evaluation and decision support. Both managers and operators share the view that current measurement systems are inadequate for managing energy. Sivill et al. (2013) especially emphasize that operating personnel lack visibility of energy performance in their daily activities and performance metrics are too focused on departmental level, leaving out the subsystem and equipment levels. Virtanen et al. (2013) also examined the complexities involved in the measurement and management of energy efficiency. They conducted a single case study at Borealis Polymers in Finland, a petrochemical company representing the energy-intensive process industry. Virtanen et al. (2013) concluded that the performance indicator used, specific energy efficiency (SEC), which is the ratio between the total energy used and the useful output of the process measured in physical units, does not allow proper energy efficiency performance management due to several challenges that arise from the fact that the indicator requires further technical development. In their view, the energy efficiency indicator is affected by various factors and employees on all levels have difficulties in understanding how the indicator value is formed.

In contrast, Drumm et al. (2013), based on a single case study of a German chemical company, describe a best practice example of how the difficult task of measuring and improving energy efficiency in a chemical plant can be successfully mastered. The company developed a so-called Structured Efficiency System for Energy (STRUCTese ${ }^{\circledR}$ ) which allows the detailed measurement and tracking of energy efficiency. Drumm et al. (2013) concluded that the system provides full transparency about the status quo as well as the further improvement potential and the result of a total energy consumption reduction of $26 \%$ for a real plant shows the benefit of such a transparent visualization of energy efficiency. Dobes (2013) asserts that even enterprises with very advanced management systems seldom monitor efficiency of energy usage within their processes and therefore have difficulties effectively managing their energy efficiency. Based on case studies of two Czech companies, he analyzed the effects of subcontracting energy service companies (ESCO) to cover this task. The results show that ESCO facilitated organizational learning by successfully providing feedback on real energy efficiency performance. This enabled the companies to see the potential for improvement, making people accountable for its exploration and obtaining verified results of implemented energy efficiency measures (Dobes, 2013).

A final predominant theme within the literature on energy management regarding controlling is the aspect of benchmarking. Peterson and Belt (2009) distinguish three different types of energy efficiency benchmarking: industry benchmark, historical benchmark, and company-wide benchmark. Industrial benchmarks, where a company's own facilities or processes are compared with facilities or processes of other companies, are usually hard to realize as other companies are mostly reluctant to share their energy efficiency values since they are considered sensitive. A historical benchmark compares actual energy consumption of a facility or a process against itself at an earlier time. In a company-wide benchmark several facilities and similar processes of the same company are compared against each other. Peterson and Belt (2009) suggest when using the concept of a company-wide 
benchmark to perform the so-called "top quartile analysis". All facilities and similar processes are compared and ranked. In the follow-up, low performing facilities and processes should be improved to the level of the top 25\%. Ke et al. (2013) provide a formal general system framework for implementing industrial energy benchmarking. The authors use a prototype of the cement industry to demonstrate the basic idea and practices of the process-based energy benchmarking approach. Ke et al. (2013) conclude that process-based benchmarking is very helpful for identifying major energy efficiency potentials, but in real-world applications, it often requires great effort to be design and implement that approach. The main reasons for this are complex interconnections between subprocesses, the natural non-homogeneity of two real industrial systems (which always implies necessary normalizations), and the difficulty of acquiring relevant and sufficient energy data for the processes (Ke et al., 2013). Bunse et al. (2011) also emphasize that in their view there is a lack of methods and criteria that allow an effective comparison between the production systems of different companies as there are only a few applicable indicators for benchmarking on plant and process level. In this regard, Stawicki et al. (2010) suggest using the specific energy consumption (SEC) and the energy efficiency index (EEI) as basis for benchmarking. Worrell and Price (2006) emphasize that benchmarking can be a very useful tool for understanding and optimizing energy use patterns in an industrial facility. They describe the development of an integrated benchmarking and energy efficiency evaluation tool, named BEST (Benchmarking and Energy Savings Tool), to support two Chinese iron and steel plants. As a result, they conclude that benchmarks should be set on the basis of energy intensity, preferably including physical measures of throughput as part of the metric, instead of economic measures. Furthermore, since facilities being compared will be somewhat similar but not identical, it is important to have an evaluation tool that compensates for variations. In a study by Hasanbeigi et al. (2010) the same tool (BEST) was used to perform a benchmarking analysis of 16 Chinese cement plants. The surveyed cement plants were compared to international and domestic (Chinese) best practice which provided an initial assessment of the technical potential for energy efficiency improvement. The average identified technical potential based on international best practice was $24 \%$, whereas based on domestic best practice it was $12 \%$. Önüt and Soner (2007) propose the data envelopment analysis (DEA), a special linear programming model, for deriving the comparative efficiency of comparable facilities. They conducted an evaluation of energy efficiency in 20 mediumsized Turkish manufacturing companies based on utility billing data and by applying the DEA methodology significant energy efficiency potentials could be revealed. Lastly, Giacone and Mancò (2012) propose another methodology to measure energy efficiency in industrial processes where the whole energy system of a facility is represented using a single matrix equation. They illustrate their methodology through two case studies from energy-intensive sectors. The results of this structured statistical approach can be used for the purpose of energy benchmarking.

\subsection{Organization}

The articles grouped under this category offer contributions regarding the necessity and accurate design of an energy manager position, as well as on integration and standardization as organizational challenges of an energy management.

Martin et al. (2012) interviewed managers of 190 randomly selected manufacturing plants in the UK and matched their responses with official business microdata. They find a strong empirical link between climate-friendly management practices and organizational structure. Firms are more likely to adopt such practices if climate change issues are managed by an environmental or energy manager, and if this manager is close to the CEO. Adoption is less likely when the CEO is in charge of climate 
change issues. They therefore cautiously interpret the findings as evidence that management practices and organizational structure of a firm are crucial for its ability to use energy more efficiently. In this regard, the position of an environmental or energy manager is of vital importance. Gordić et al. (2010) complement these findings in their case study of a Serbian car manufacturer by also emphasizing that regardless of the type of organizational structure of a company and a respective energy management organization, the most crucial spot is the position of an energy manager. They advise that this position should have direct access to top management and a strong cross-functional information base. Kannan and Boie (2003) in their case study on energy management practices in SME however highlight the issue that SME normally cannot afford to appoint a dedicated energy manager because the potential energy savings would not be able to pay-off the position. Ates and Durakbasa (2012) within their study on energy management practices of energy-intensive industries in Turkey finally provide a list of relevant tasks for the position of an energy manager: development of an energy management action plan, identification of financing sources, development of a well-functioning organizational structure, establishment and implementation of energy efficiency measures, preparation of internal communication and assessment of effectiveness of the energy management program.

Bunse et al. (2011) highlight the need for industrial companies to integrate energy management into production management processes and emphasize the importance of ICT tools and standardization as enablers for energy-efficient manufacturing. ICT tools may support the control of production processes as well as the evaluation and assessment of potential energy-saving investments whereas standardization increases the transparency of companies' processes. Amundsen (2000) also picks up the integration aspect in regard to energy management. Based on the analysis of environmental statements from 13 Norwegian energy-intensive companies as well as 10 additional case studies comprising energy-intensive, small and medium-sized Norwegian food processing companies, he concludes that energy management is separated from environmental management systems (EMS) in Norwegian industry. As in his view integrating energy management into EMS avoids parallel management systems and enables greater economic savings and environmental performance improvements, he argues for the joint management of energy and environmental aspects within companies.

Lastly, based upon the results of a telephone survey covering 304 Danish industrial firms, Christoffersen et al. (2006) reveal three different types of energy management in Danish industry. One type of company is strong in general organizational aspects, but weak in energy-specific aspects, including the realization of concrete energy efficiency projects. In contrast, another type of company might especially need to strengthen the organizational parts of their energy management to make them an ongoing process within the company. The third and last type of company needs general motivation to engage in energy management.

\subsection{Culture}

The articles grouped under this category offer contributions on the factors education/training, staff motivation and internal communication as key elements of an energy management.

In their conceptual study on energy management in the French industry, Lesourd and Ruiz (1984) first identify and articulate specific needs in regard to human resources management. In particular, in their view, energy managers, regardless of whether they are employed at corporate level or at plant level, need to match specific manpower requirements in regard to basic education which needs to be taken into account. Furthermore, they emphasize an induced specific need for a continuous energy-related 
training program within companies. Two empirical studies are in addition able to confirm the often postulated positive impact of continuous training as part of an energy management. Liu et al. (2012) conducted an empirical study based on a sample of 125 small and medium-sized companies in Taicang, China. They measure industrial energy saving activities (ESAs) within the sample companies and try to identify their major determinant factors by using an econometric analysis. Among other results, they investigate that internal training on energy saving as an internal factor has a significant and positive influence on a company's involvement level in regard to ESAs. In a similar study in Korea, Suk et al. (2013) expand this finding by showing that as internal factors the willingness for energy saving, support from top management and internal training on energy saving determine a company's practice level of ESAs. Lastly, Bowonder (1984) asserts that energy management activity will not percolate to industries unless senior business executives are convinced of the potential of an energy management and fully support its implementation. In this regard he emphasizes the importance of energy management training and awareness programs for senior company executives.

Other crucial elements of a well-functioning energy management are encouragement measures carried out by an organization in order to motivate staff to actively participate in enhancing energy efficiency. In this regard, Stawicki et al. (2010) recommend in case of successes the recognition of achievements by providing rewards for operational and technical staff. In their view, this helps to sustain the momentum and to increase the overall support for the energy management program. However, Ates and Durakbasa (2012) within their study on energy management practices of energy-intensive industries in Turkey exemplarily show that these kinds of measures are often not considered by companies. Of their surveyed companies, 58\% indicate that no staff awareness program is in place. Even those companies that indicate having encouragement measures in place, mostly only use signs or stickers to encourage staff to turn off lights or equipment.

Another motivational factor within energy management is top management involvement. Based on a sample of 752 small and medium-sized U.S. manufacturing firms, Blass et al. (2014) empirically investigate the role of top managers in the adoption of energy-efficiency practices. They find that the involvement of top operations managers with a clearly operationally-focused position significantly increases the adoption of energy-efficiency initiatives, while involvement of general top managers without an operational role has little or no effect.

As a final cultural component of energy management, Peterson and Belt (2009) emphasize the importance of effective communication. In their view, the individual corporate culture has to be taken into account when selecting tools of communication. They have successfully used a set of tools comprised of reports at monthly business meetings, monthly letters detailing specific results, internal web sites and directed memos. According to an empirical study of Christoffersen et al. (2006) on energy management practices in Danish industry, $44 \%$ of the surveyed companies seek to actively involve their employees by means of "passive" information (e.g. on a notice board).

After having presented the synthesized findings of the reviewed body of literature, we proceed by conceptualizing the identified key elements and diverse activities into an integrative energy management framework. 


\section{Conceptualization of an integrative corporate energy management framework}

Figure 8 illustrates an integrative energy management framework comprising the previously identified five key elements and associated actions. The framework represents a continuous improvement circle which companies need to run through again and again.

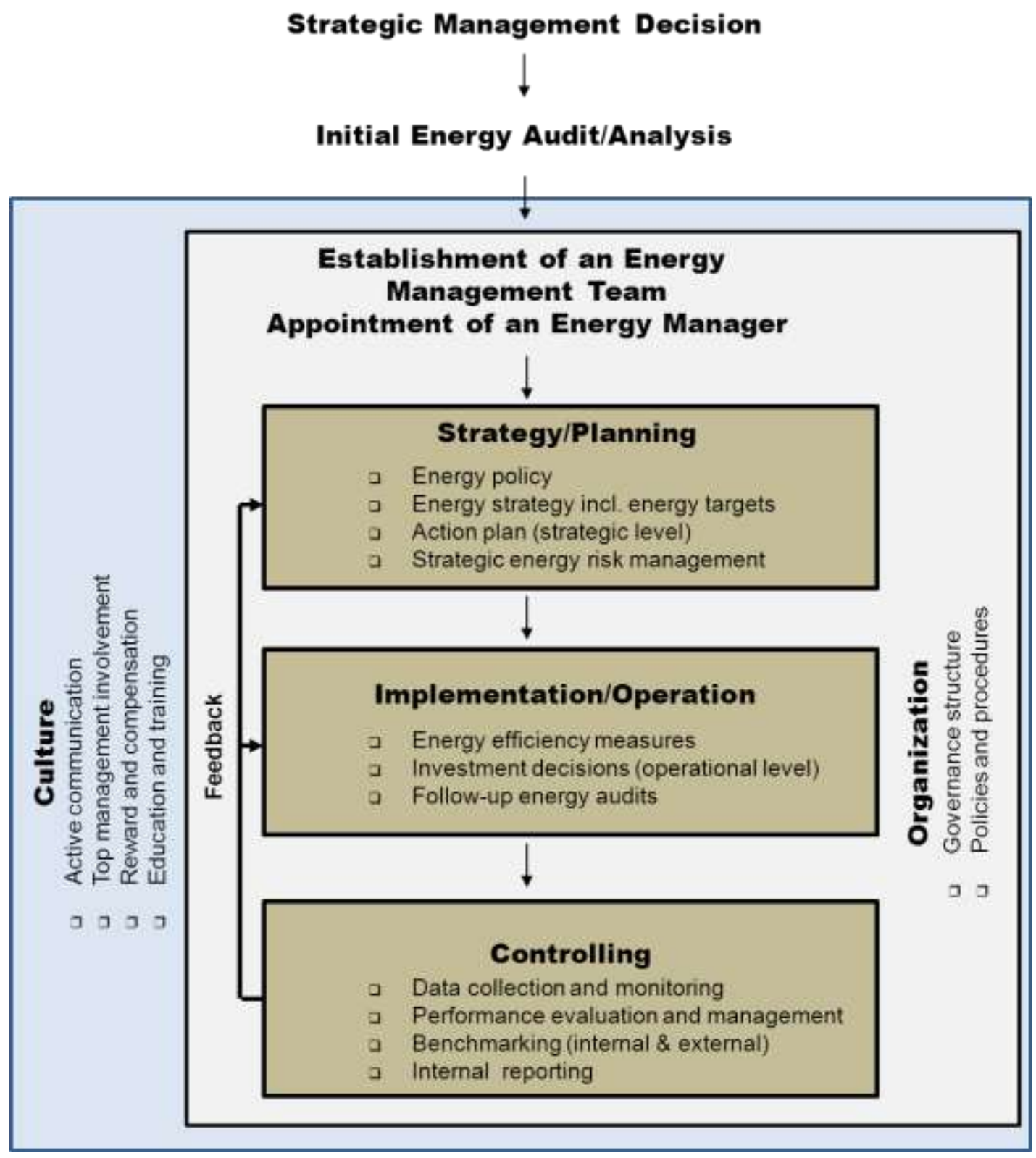

Figure 8: Framework of an integrative energy management

The starting point is set by a strategic management decision which forms the basis for the implementation of an energy management. Following this, a responsible energy management team (energy committee) needs to be established. This team should be cross-functional and led by a responsible energy coordinator (energy manager) who reports directly to management (González et al., 2012; Martin et al., 2012; McKane et al., 2007). As a next step, the energy-related status quo of the 
company should be determined. For this purpose, an initial energy audit (also called energy analysis or energy evaluation) needs to be performed. An energy audit is a formal, systematic procedure that analyzes the current energy flows of a company. The purpose is thereby to identify the companyspecific main energy processes and consumers, to quantify the energy use, and to identify and analyze potential to enhance energy efficiency (Abdelaziz et al., 2011; Gordić et al., 2010).

Based on the results of the initial energy audit, the energy management team has to develop an energy policy/energy strategy including long- and short-term energy targets (Ates \& Durakbasa, 2012; Lambert \& Stock, 1979; Rudberg et al., 2013; Thollander \& Ottosson, 2010). Those documents need to be closely connected with the general corporate strategy as energy management has to contribute to the overall corporate purpose. Within the planning process, the company-specific energy-related targets must additionally be operationalized from an overall company perspective to the level of business groups, functional areas and, if relevant, the plant/facility level (Rietbergen \& Blok, 2010). The energy-specific target-setting process is complemented by action planning on a strategic level which develops specific short- and long-term measures to achieve the energy targets (Gordić et al., 2010; Peterson \& Belt, 2009). As a final strategic component of an energy management, a strategic energy risk management (SERM) analyzes the exposure of the company to relevant components of risk related to its energy use and manages it in the context of the company's predetermined financial objectives and risk tolerances (Vasudevan \& Higgins, 2004).

The implementation element focuses on the operational level of an energy management. Based on the action plan developed in the strategic planning process, different energy efficiency measures and actions, which can be of a technical, organizational or management nature (Caffal, 1995; Fleiter et al., 2012a; McKane et al., 2007), will be implemented. This element also includes operational decisions regarding the acquisition, allocation, utilization and disposition of resources, especially regarding financial investments by calculating and approving payback periods (Peterson \& Belt, 2009; Sandberg \& Söderström, 2003). Follow-up energy audits and management reviews need to be continuously conducted to reveal new potential for optimization (Abdelaziz et al., 2011; Kannan \& Boie, 2003; McKane et al., 2007).

The controlling element ensures the constant collection of energy-related data, including financial and particularly non-financial aspects, within an energy information system and thereby monitors the energy use and related energy costs of a company (Bunse et al., 2011; Drumm et al., 2013; Kannan \& Boie, 2003). Furthermore, it defines key performance indicators (KPI), measures and evaluates the performance effects of the implemented energy efficiency measures, benchmarks against internal and external objects of comparison and suggests, if necessary, corrective actions (Bunse et al., 2011; McKane et al., 2007; Sivill et al., 2013). By periodically reporting the energy use and related energy costs to management, a performance-related feedback loop is ensured (Abdelaziz et al., 2011).

The organizational element of energy management comprises two main aspects: governance structure within the company and policies and procedures. The governance structure aims to define formal lines of authority and responsibility (Abdelaziz et al., 2011; Christoffersen et al., 2006). The use of policies and procedures aims at addressing all aspects of the corporate energy value chain regarding procurement, conversion, distribution and use of energy (Ates \& Durakbasa, 2012; Jelić et al., 2010; McKane et al., 2007).

The top management should be the initiator and reliable sponsor of a company-wide energy culture and supporter of an active communication of energy-related issues both within the company and externally. The energy culture also includes aspects like top management involvement in the energy- 
related decision-making process (Blass et al., 2014), reward and compensation on individual and group level (Stawicki et al., 2010) and finally energy-related education and training (Bowonder, 1984; Lesourd \& Ruiz, 1984).

\section{Discussion}

Research states that there is large, still unexploited energy efficiency potential in industrial companies (Backlund et al., 2012). Our paper presents a general energy management framework that enables a comprehensive approach to energy management in industrial organizations. In our view, such an approach is a very important internal driving force for industrial companies in order to further close the energy efficiency gap by linking improved energy efficiency to strategy, routinizing processes, performance indicators, responsibility and accountability, and stressing the importance of the energy issue in the organization. By implementing the energy management framework, where all five key elements are represented and equally considered, it is more likely that energy efficiency increases in industrial companies. This is due to the fact that the energy management framework encourages both the implementation of energy efficiency measures and activities and the continuous maintenance of these activities over time.

When conducting a systematic review as in our paper and developing an integrative conceptual framework, a general approach is needed. Unlike for example Bunse et al. (2011), who differentiate energy management in relation to different production systems, our framework does not explicitly take different contingency factors such as company size, type of production system, regions etc. into account. It is however of great importance to underscore that contingency factors such as the type of production greatly affect how energy management has to be carried out within an industrial company. For example, energy-intensive industries have their major energy use in the production processes whereas for non-energy-intensive industries, the major energy using processes are to be found among the support processes (cooling, heating, etc.). Therefore it has to be noted that although our general framework is applicable for any type of industrial company, the exact way how the five key elements and associated actions are carried out in practice may differ.

The large number of various definitions of energy management presented in Table 1 comprises contributions from a variety of scientific disciplines. In this paper and based on our systematic review of academic studies published in scientific journal articles, we define industrial energy management as follows: "Energy management comprises the systematic activities, procedures and routines within an industrial company including the elements strategy/planning, implementation/operation, controlling, organization and culture and involving both production and support processes, which aim to continuously reduce the company's energy consumption and its related energy costs". In the following section, we summarize our research and finally focus on the implications for further research.

\section{Conclusions}

Our research provides a systematic literature review on energy management in industry covering 44 selected scientific journal articles. Five essential key elements of an energy management based on overarching themes have been identified within the body of literature (strategy/planning, implementation/operation, controlling, organization and culture) and the specific findings relating to 
each key element have been synthesized. As an important outcome of this paper we subsequently propose a conceptual framework of an energy management. The framework illustrates that a comprehensive approach is necessary in order to effectively exploit existing energy efficiency potential.

For practitioners in industry, the results of our systematic review represent a beneficial knowledge base from a multitude of academic studies and may be helpful in identifying various approaches to further improve their energy management. Additionally, this study presents an integrative framework that is applicable for industrial organizations in various contexts. Even though the way how the five key elements and associated actions are carried out in practice may differ from company to company, the framework provides general support for improving industrial energy efficiency.

For academics, our research reveals interesting future research implications for the field of energy management. The descriptive analysis illustrates an evolving research field with increasing consideration in academic journals especially in the last three years, but one that is still of variable quality in terms of research methodologies. Existing studies are largely prescriptive, conceptual and tend to be dominated by case studies. Future research on energy management in industry therefore should consider a broader set of research methods. Longitudinal studies, especially on company level, are rare and should be taken more into consideration to study the long-term effects of various measures. Causal relationships have also not been explored extensively; only one study notes a correlation between energy management practices and environmental performance but was not able to show an impact on economic performance (Pons et al., 2013). Likewise findings are also applicable regarding the contextual dimensions (geographical focus, company size and industry sector focus) of the research on energy management. Future empirical research in this regard should especially focus on transnational and non-energy-intensive industrial contexts, which are currently underrepresented.

Concerning the thematic research focus, the descriptive analysis revealed an imbalance in the literature in the direction of the implementation of various energy efficiency measures which is clearly dominated by a technical perspective. In our view, the existing studies lack best-practice examples of achieving enhanced energy efficiency by adopting new routines and implementing adapted processes within energy management. Furthermore, the analyzed papers have a strong internal focus whereas energy services by ESCOs as a means to improve energy management are rarely addressed. Further research therefore could focus on the role and potential of ESCOs in closing the existing energy efficiency gap. Finally, the imbalance in the existing literature also suggests that the strategic dimension of an energy management should receive more attention in future research. As governments in general tend to push for energy-saving initiatives and energy prices tend to constantly increase, industrial companies will most likely be forced to put a higher focus on energy management on a strategic level (Rudberg et al., 2013). Future research therefore should examine the specific mechanisms dealing with the process of strategy implementation by utilizing resources and influencing individual and/or collective action towards energy-related objectives.

Finally, based on the extensive review of the energy management literature, the paper proposes a conceptualization of an integrative energy management framework. Future research is suggested in order to validate and complement the framework in accordance with future research findings. Such research should especially focus on empirical studies regarding the implementation and application of the framework as well as on outcomes. Hopefully this will support the future improvement of industrial energy efficiency as well as the energy management research field. 
As with any research effort, there are some limitations to this paper. The first constraint relates to the characteristics of database searches. Databases are constantly being updated with new journal articles, therefore the data collected for this study only represents a "snapshot" of data in the databases during the period of data collection. We also might have missed some potentially relevant scientific journal articles, although we followed a detailed and structured search process as presented in the method section of this paper. As a last constraint, our sample only consists of academic journal articles. This decision is based on the valuation that those articles with their rigorous peer-review process represent the most important source of evidence. However, further additional sources such as books, contributions to edited volumes and conference papers may also provide additional evidence of knowledge transfer, but were not considered in our paper. 


\section{Appendix}

Articles included in the systematic review

\begin{tabular}{|c|c|c|c|c|c|c|}
\hline \multirow[b]{2}{*}{ Article } & \multirow[b]{2}{*}{ Journal } & \multirow[b]{2}{*}{ Type of Study } & \multicolumn{3}{|c|}{ Contextual dimensions (if specified) } & \multirow{2}{*}{$\begin{array}{c}\text { Research } \\
\text { Focus by } \\
\text { Categories }^{\mathrm{a}}\end{array}$} \\
\hline & & & $\begin{array}{l}\text { Geographical } \\
\text { Focus }\end{array}$ & $\begin{array}{l}\text { Company } \\
\text { Size } \\
\text { Focus }\end{array}$ & $\begin{array}{l}\text { Industry Sector } \\
\text { Focus }\end{array}$ & \\
\hline Abdelaziz et al. (2011) & $\begin{array}{l}\text { Renewable and Sustainable } \\
\text { Energy Reviews }\end{array}$ & Literature Review & Multiple & --- & --- & I \\
\hline Aflaki et al. (2013) & $\begin{array}{l}\text { Production and Operations } \\
\text { Management }\end{array}$ & $\begin{array}{c}\text { Conceptual/ } \\
\text { Single Case Study }\end{array}$ & Germany & Large & Pharmaceutical & I \\
\hline Alcorta et al. (2014) & Energy Efficiency & Survey & $\begin{array}{c}\text { Developing } \\
\text { Countries }\end{array}$ & Diverse & Diverse & I \\
\hline Amundsen (2000) & Journal of Cleaner Production & $\begin{array}{c}\text { Mixed Method Approach } \\
\text { (Secondary Data Analysis, } \\
\text { Interviews, Case Study) }\end{array}$ & Norway & Diverse & $\begin{array}{l}\text { Manufacturing, } \\
\text { Food Processing }\end{array}$ & $\mathrm{O}$ \\
\hline Apeaning \& Thollander (2013) & Journal of Cleaner Production & Interviews & Ghana & --- & Diverse & I \\
\hline Ates \& Durakbasa (2012) & Energy & Survey & Turkey & Diverse & Diverse & $\mathrm{S}, \mathrm{O}, \mathrm{Cu}$ \\
\hline Blass et al. (2014) & Energy & $\begin{array}{c}\text { Mixed Method Approach } \\
\text { (Secondary Data Analysis, } \\
\text { Interviews, Observations, } \\
\text { Statistical Analysis) } \\
\end{array}$ & United States & SME & Manufacturing & $\mathrm{Cu}$ \\
\hline Bowonder (1984) & The Environmentalist & Conceptual & India & --- & --- & $\mathrm{Cu}$ \\
\hline Bunse et al. (2011) & Journal of Cleaner Production & $\begin{array}{c}\text { Mixed Method Approach } \\
\text { (Literature Review, } \\
\text { Interviews, Workshop, } \\
\text { Survey) } \\
\end{array}$ & $\begin{array}{l}\text { EU, Norway, } \\
\text { Switzerland, } \\
\text { Japan, Korea, } \\
\text { United States }\end{array}$ & --- & Manufacturing & $\mathrm{C}, \mathrm{O}$ \\
\hline Christoffersen et al. (2006) & Journal of Cleaner Production & Survey & Denmark & Mostly SME & Manufacturing & $\mathrm{I}, \mathrm{C}$ \\
\hline Dobes (2013) & Journal of Cleaner Production & Case Study & Czech Republic & Diverse & Manufacturing & $\mathrm{C}$ \\
\hline Drumm et al. (2013) & $\begin{array}{l}\text { Chemical Engineering and } \\
\text { Processing: Process } \\
\text { Intensification }\end{array}$ & $\begin{array}{l}\text { Conceptual/ } \\
\text { Case Study }\end{array}$ & Germany & Large & Chemical & $\mathrm{C}$ \\
\hline
\end{tabular}

${ }^{\text {a }} \mathrm{S}=$ Strategy/Planning, $\mathrm{I}=$ Implementation/Operation, $\mathrm{C}=$ Controlling, $\mathrm{O}=$ Organization, $\mathrm{Cu}=\mathrm{Culture}$ 
Articles included in the systematic review (continued)

\begin{tabular}{|c|c|c|c|c|c|c|}
\hline \multirow[b]{2}{*}{ Article } & \multirow[b]{2}{*}{ Journal } & \multirow[b]{2}{*}{ Type of Study } & \multicolumn{3}{|c|}{ Contextual dimensions (if specified) } & \multirow{2}{*}{$\begin{array}{c}\text { Research } \\
\text { Focus by } \\
\text { Categories }^{\mathrm{a}}\end{array}$} \\
\hline & & & $\begin{array}{l}\text { Geographical } \\
\text { Focus }\end{array}$ & $\begin{array}{l}\text { Company } \\
\text { Size } \\
\text { Focus } \\
\end{array}$ & $\begin{array}{l}\text { Industry Sector } \\
\text { Focus }\end{array}$ & \\
\hline Fleiter et al. (2012a) & Energy Policy & Conceptual & --- & --- & --- & I \\
\hline Giacone \& Mancò (2012) & Energy & Theoretical/Case Study & Italy & --- & Glass, Iron & $\mathrm{C}$ \\
\hline Gordic et al. (2010) & $\begin{array}{l}\text { Energy Conversion and } \\
\text { Management }\end{array}$ & Single Case Study & Serbia & Large & Automotive & $\mathrm{I}, \mathrm{O}$ \\
\hline Gruber \& Brand (1991) & Energy Policy & Interviews, Survey & Germany & SME & Diverse & I \\
\hline Hasanbeigi et al. (2010) & Energy & Case Study & China & --- & Cement & $\mathrm{C}$ \\
\hline Hasanbeigi \& Price (2012) & $\begin{array}{l}\text { Renewable and Sustainable } \\
\text { Energy Reviews }\end{array}$ & Literature Review & --- & Diverse & Textile & I \\
\hline Jackson (2010) & Energy Policy & Conceptual/Theoretical & --- & --- & --- & I \\
\hline Kannan \& Boie (2003) & $\begin{array}{l}\text { Energy Conversion and } \\
\text { Management }\end{array}$ & Single Case Study & Germany & SME & Bakery & $\mathrm{I}, \mathrm{C}, \mathrm{O}$ \\
\hline Ke et al. (2013) & Energy & Theoretical & --- & --- & --- & $\mathrm{C}$ \\
\hline Lambert \& Stock (1979) & Long Range Planning & Survey & United States & --- & Diverse & S \\
\hline Lesourd \& Ruiz (1984) & $\begin{array}{l}\text { Engineering Management } \\
\text { International }\end{array}$ & Conceptual & France & --- & --- & $\mathrm{Cu}$ \\
\hline Liu et al. (2012) & Journal of Cleaner Production & Survey & China & SME & Diverse & $\mathrm{I}, \mathrm{Cu}$ \\
\hline Martin et al. (2012) & $\begin{array}{l}\text { Journal of Environmental } \\
\text { Economics and Management }\end{array}$ & Interviews & United Kingdom & Large & Manufacturing & $\mathrm{S}, \mathrm{O}$ \\
\hline Mills et al. (2008) & Energy Efficiency & Conceptual & United States & --- & Manufacturing & I \\
\hline Önüt \& Soner (2007) & $\begin{array}{l}\text { Energy Conversion and } \\
\text { Management }\end{array}$ & Survey & Turkey & SME & Metallic Goods & $\mathrm{C}$ \\
\hline Peterson \& Belt (2009) & $\begin{array}{l}\text { The Journal of the Minerals, } \\
\text { Metals \& Materials Society } \\
\text { (JOM) }\end{array}$ & Conceptual & --- & --- & --- & $\mathrm{C}, \mathrm{Cu}$ \\
\hline
\end{tabular}

${ }^{\text {a }} \mathrm{S}=$ Strategy/Planning, $\mathrm{I}=$ Implementation/Operation, $\mathrm{C}=$ Controlling, $\mathrm{O}=$ Organization, $\mathrm{Cu}=$ Culture 
Articles included in the systematic review (continued)

\begin{tabular}{|c|c|c|c|c|c|c|}
\hline \multirow[b]{2}{*}{ Article } & \multirow[b]{2}{*}{ Journal } & \multirow[b]{2}{*}{ Type of Study } & \multicolumn{3}{|c|}{ Contextual dimensions (if specified) } & \multirow{2}{*}{$\begin{array}{c}\text { Research } \\
\text { Focus by } \\
\text { Categories }\end{array}$} \\
\hline & & & $\begin{array}{l}\text { Geographical } \\
\text { Focus }\end{array}$ & $\begin{array}{c}\text { Company } \\
\text { Size } \\
\text { Focus } \\
\end{array}$ & $\begin{array}{l}\text { Industry Sector } \\
\text { Focus }\end{array}$ & \\
\hline Pons et al. (2013) & Journal of Cleaner Production & Survey & Spain, Slovenia & Diverse & Manufacturing & I \\
\hline Pye \& McKane (2000) & $\begin{array}{l}\text { Resources, Conservation and } \\
\text { Recycling }\end{array}$ & Conceptual, Case Study & United States & --- & Diverse & I \\
\hline Rietbergen \& Blok (2010) & Energy Policy & Conceptual & --- & --- & --- & $\mathrm{S}$ \\
\hline Rudberg et al. (2013) & Applied Energy & Single Case Study & Sweden & Large & Chemical & S \\
\hline Sandberg \& Söderström (2003) & Energy Policy & Interviews & Sweden & --- & Diverse & I \\
\hline Sivill et al. (2013) & $\begin{array}{l}\text { International Journal of } \\
\text { Energy Research }\end{array}$ & Case Study & Finland & --- & Diverse & $\mathrm{C}$ \\
\hline Stawicki et al. (2010) & $\begin{array}{l}\text { Cellulose Chemistry and } \\
\text { Technology }\end{array}$ & Conceptual & --- & --- & Pulp and Paper & $\mathrm{C}, \mathrm{Cu}$ \\
\hline Stenqvist \& Nilsson (2012) & Energy Efficiency & Case Study & Sweden & --- & Manufacturing & I \\
\hline Suk et al. (2013) & Journal of Cleaner Production & Survey & Korea & Diverse & Diverse & $\mathrm{I}, \mathrm{Cu}$ \\
\hline Thollander \& Ottosson (2010) & Journal of Cleaner Production & Case Study & Sweden & --- & $\begin{array}{l}\text { Pulp and Paper, } \\
\text { Foundry }\end{array}$ & $\mathrm{S}, \mathrm{I}, \mathrm{C}$ \\
\hline Trianni et al. (2014) & Applied Energy & Literature Review & --- & --- & --- & I \\
\hline Vasudevan \& Higgins (2004) & $\begin{array}{l}\text { The Journal of Structured and } \\
\text { Project Finance }\end{array}$ & Theoretical & --- & --- & --- & S \\
\hline Virtanen et al. (2013) & $\begin{array}{l}\text { Management Accounting } \\
\text { Research }\end{array}$ & Single Case Study & Finland & Large & Petrochemical & $\mathrm{C}$ \\
\hline Worrell et al. (2003) & Energy & Case Study & --- & --- & Diverse & I \\
\hline Worrell \& Price (2006) & $\begin{array}{l}\text { International Journal of Green } \\
\text { Energy }\end{array}$ & Conceptual & China & --- & Iron and Steel & $\mathrm{C}$ \\
\hline Zhang \& Wang (2008) & Energy & Empirical & China & --- & Iron and Steel & I \\
\hline
\end{tabular}

${ }^{\text {a }} \mathrm{S}=$ Strategy/Planning, $\mathrm{I}=$ Implementation/Operation, $\mathrm{C}=$ Controlling, $\mathrm{O}=$ Organization, $\mathrm{Cu}=$ Culture 


\section{References}

Abdelaziz, E. A., Saidur, R., Mekhilef, S., 2011. A review on energy saving strategies in industrial sector. Renewable and Sustainable Energy Reviews 15 (1), 150-168.

Aflaki, S., Kleindorfer, P. R., de Miera Polvorinos, V. S., 2013. Finding and Implementing Energy Efficiency Projects in Industrial Facilities. Production and Operations Management 22 (3), 503-517.

Alcorta, L., Bazilian, M., De Simone, G., Pedersen, A., 2014. Return on investment from industrial energy efficiency: evidence from developing countries. Energy Efficiency 7 (1), 43-53.

Amundsen, A., 2000. Joint management of energy and environment. Journal of Cleaner Production 8 (6), 483 494.

Apeaning, R. W., Thollander, P., 2013. Barriers to and driving forces for industrial energy efficiency improvements in African countries - a case study of Ghana's largest industrial area. Journal of Cleaner Production 53, 204-213.

Association of German Engineers, 2007. VDI Guideline 4602 Part I. Energy management - Terms and definitions.

Ates, S.A., Durakbasa, N. M., 2012. Evaluation of corporate energy management practices of energy intensive industries in Turkey. Energy 45 (1), 81-91.

Backlund, S., Thollander, P., Palm, J., Ottosson, M., 2012. Extending the energy efficiency gap. Energy Policy 51, 392-396.

Blass, V., Corbett, C. J., Delmas, M. A., Muthulingam, S., 2014. Top management and the adoption of energy efficiency practices: Evidence from small and medium-sized manufacturing firms in the US. Energy 65, 560-571.

Bowonder, B., 1984. Energy Management Awareness Programme for Senior Executives. The Environmentalist 4 (2), 125-129.

Brunke, J.-C., Johansson, M., Thollander P., 2014. Empirical investigation of barriers and drivers to the adoption of energy conservation measures, energy management practices and energy services in the Swedish iron and steel industry. Journal of Cleaner Production 84 (1), 509-525.

Bunse, K., Vodicka, M., Schoensleben, P., Brülhart, M., Ernst, F. O., 2011. Integrating energy efficiency performance in production management - gap analysis between industrial needs and scientific literature. Journal of Cleaner Production 19 (6-7), 667-679.

Caffal, C., 1995. Energy management in industry. Centre for the Analysis and Dissemination of Demonstrated Energy Technologies (CADDET). Analysis Series 17, Sittard, The Netherlands.

Capehart, B. L., Turner, W. C., Kennedy, W. J., 2008. Guide to Energy Management, 6th ed. The Fairmont Press, Lilborn.

Christoffersen, L. B., Larsen, A., Togeby, M., 2006. Empirical analysis of energy management in Danish industry. Journal of Cleaner Production 14 (5), 516-526.

Denyer, D., Tranfield, D., 2009. Producing a Systematic Review, in: Buchanan, D. A., Bryman, A. (Eds.), The SAGE Handbook of Organizational Research Methods. SAGE Publications Ltd., London, pp. 671-689.

Dobes, V., 2013. New tool for promotion of energy management and cleaner production on no cure, no pay basis. Journal of Cleaner Production 39, 255-264.

Drumm, C., Busch, J., Dietrich, W., Eickmanns, J., Jupke, A., 2013. STRUCTese® - Energy efficiency management for the process industry. Chemical Engineering and Processing: Process Intensification 67, 99110.

Fleiter, T., Hirzel, S., Worrell, E., 2012a.The characteristics of energy-efficiency measures - a neglected dimension. Energy Policy 51, 502-513.

Fleiter, T., Gruber, E., Eichhammer, W., Worrell, E., 2012b. The German energy audit program for firms - a cost-effective way to improve energy efficiency? Energy Efficiency 5 (4), 447-469.

German Energy Agency (2010). Handbook for corporate energy management - Systematically reducing energy costs. Berlin (in German).

German Federal Environment Agency (2014). Number of ISO 50001 certified sites worldwide. www.nagus.din.de/sixcms_upload/media/2612/2014-05-30\%20Chart\%20ISO\%2050001\%20Worldwide.pdf (accessed 15.05.2015).

German Federal Environment Agency (2012). Energy management systems within practice - ISO 50001: handbook for companies and organizations. www.umweltbundesamt.de/sites/default/files/medien/ publikation/long/3959.pdf (in German, accessed 15.05.2015). 
German Federal Statistical Office (2015). Data on the development of energy prices - Series from January 2000 to March 2015. www.destatis.de/DE/Publikationen/Thematisch/Preise/Energiepreise/Energiepreisentwick lungPDF_5619001.pdf?_blob=publicationFile (in German, accessed 15.05.2015).

Giacone, E., Mancò, S., 2012. Energy efficiency measurement in industrial processes. Energy 38, 331-345.

Glaser, B., Strauss, A., 1967. The Discovery of Grounded Theory. Aldine, Chicago.

González, A. J., Castrillón, R.,Quispe, E. C., 2012. Energy efficiency improvement in the cement industry through energy management. Proceedings of the Cement Industry Technical Conference, 2012 IEEEIAS/PCA 53 ${ }^{\text {rd }}$, San Antonio, Texas, USA, 14-17 May 2012.

Gordić, D., Babić, M., Jovičić, N., Šušteršič, V., Končalović, D., Jelić, D., 2010. Development of energy management system - Case study of Serbian car manufacturer. Energy Conversion and Management 51 (12), 2783-2790.

Gruber, E., Brand, M., 1991. Promoting energy conservation in small and medium-sized companies. Energy Policy 19 (3), 279-287.

Hasanbeigi, A., Price, L., 2012. A review of energy use and energy efficiency technologies for the textile industry. Renewable and Sustainable Energy Reviews 16 (6), 3648-3665.

Hasanbeigi, A., Price, L., Lu, H., Lan, W., 2010. Analysis of energy-efficiency opportunities for the cement industry in Shandong Province, China: A case study of 16 cement plants. Energy 35 (8), 3461-3473.

Hirst, E., Brown, M., 1990. Closing the efficiency gap: barriers to the efficient use of energy. Resources, Conservation and Recycling 3 (4), 267-281.

International Energy Agency, 2012. World Energy Outlook 2012 - Executive Summary. www.iea.org/publications/freepublications/publication/English.pdf (accessed 15.05.2015).

International Energy Agency, 2007. Tracking Industrial Energy Efficiency and $\mathrm{CO}_{2}$ Emissions. www.iea.org/publications/freepublications/publication/tracking_emissions.pdf (accessed 15.05.2015).

International Organization of Standardization, 2011. ISO 50001:2011, Energy management systems Requirements with guidance for use.

Jackson, J., 2010. Promoting energy efficiency investments with risk management decision tools. Energy Policy 38 (8), 3865-3873.

Jelić, D. N., Gordić, D. R., Babić , M. J., Končalović, D. N., Šušteršič V. M., 2010. Review of existing energy management standards and possibilities for its introduction in Serbia. Thermal Science 14 (3), 613-623.

Kannan, R., Boie, W., 2003. Energy management practices in SME - case study of a bakery in Germany. Energy Conversion and Management 44 (6), 945-959.

Ke, J., Price, L., McNeil, M., Khanna, N. Z., Zhou, N., 2013. Analysis and practices of energy benchmarking for industry from the perspective of systems engineering. Energy 54, 32-44.

Lambert, D. M., Stock, J. R., 1979. The Corporate Energy Policy: A Management Planning Perspective. Long Range Planning 12 (2), 45-51.

Lesourd, J.-B., Ruiz, J.-M, 1984. Human Resources for Energy Management: The Case of French Industry. Engineering Management International 2 (3), 195-198.

Liu, X., Niu, D., Bao, C., Suk, S., Shishime, T. 2012. A survey study of energy saving activities of industrial companies in Taicang, China. Journal of Cleaner Production 26, 79-89.

Martin, R., Muûls, M., de Preux, L. B., Wagner, U. J., 2012. Anatomy of a paradox: Management practices, organizational structure and energy efficiency. Journal of Environmental Economics and Management 63 (2), 208-223.

McKane, A., Williams, R., Perry, W., Li, T., 2007. Setting the Standard for Industrial Energy Efficiency. Proceedings of Conference on Energy Efficiency in Motor Driven Systems (EEMODS 07), topic \#9, paper \#070.

Mills, E., Shamshoian, G., Blazek, M., Naughton, P., Seese, R. S., Tschudi, W., Sartor, D., 2008. The business case for energy management in high-tech industries. Energy Efficiency 1, 5-20.

O’Callaghan, P. W., Probert, S. D., 1977. Energy management. Applied Energy 3 (2), 127-138.

Önüt, S., Soner, S., 2007. Analysis of energy use and efficiency in Turkish manufacturing sector SMEs. Energy Conversion and Management 48 (2), 384-394.

Peterson, R. D., Belt, C. K., 2009. Elements of an Energy Management Program. The Journal of The Minerals, Metals \& Materials Society (JOM) 61 (4), 19-24.

Podsakoff, P. M., Mackenzie, S. B., Bachrach, D. G., Podsakoff, N. P., 2005. The influence of management journals in the 1980 and 1990. Strategic Management Journal 26(5), 473-488.

Pons, M., Bikfalvi, A., Llach, J., Palcic, I., 2013. Exploring the impact of energy efficiency technologies on manufacturing firm performance. Journal of Cleaner Production 52, 134-144.

Pye, M., McKane, A., 2000. Making a stronger case for industrial energy efficiency by quantifying non-energy benefits. Resources, Conservation and Recycling 28 (3-4), 171-183.

Rietbergen, M. G., Blok, K., 2010. Setting SMART targets for industrial energy use and industrial energy efficiency. Energy Policy 38 (8), 4339-4354. 
Rohdin, P., Thollander, P., 2006. Barriers to and driving forces for energy efficiency in the non-energy intensive manufacturing industry in Sweden. Energy 31 (12), 1836-1844.

Rudberg, M., Waldemarsson, M., Lidestam, H., 2013. Strategic perspectives on energy management: A case study in the process industry. Applied Energy 104, 487-496.

Sandberg, P., Söderström, M., 2003. Industrial energy efficiency: the need for investment decision support from a manager perspective. Energy Policy 31 (15), 1623-1634.

Saygin, D., Worrell, E., Patel, M. K., Gielen, D. J., 2011. Benchmarking the energy use of energy-intensive industries in industrialized and in developing countries. Energy 36 (11), 6661-6673.

Shen, B., Price, L., Lu, H., 2012. Energy audit practices in China: National and local experiences and issues. Energy Policy 46, 346-358.

Sivill, L., Manninen, J., Hippinen, I., Ahtila, P., 2013. Success factors of energy management in energy-intensive industries: Development priority of energy performance measurement. International Journal of Energy Research 37 (8), 936-951.

Stawicki, B., Lozo, B., Lajić, B., 2010. Energy management guidelines in pulp and paper production. Cellulose Chemistry and Technology 44 (10), 521-529.

Stenqvist, C., Nilsson, L. J., 2012. Energy efficiency in energy-intensive industries - an evaluation of the Swedish voluntary agreement PFE. Energy Efficiency 5 (2), 225-241.

Strauss, A., Corbin, J., 1990. Basics of Qualitative Research. Sage, Newbury Park, CA.

Suk, S., Liu, X., Sudo, K., 2013. A survey study of energy saving activities of industrial companies in the Republic of Korea. Journal of Cleaner Production 41, 301-311.

Tanaka, K., 2011. Review of policies and measures for energy efficiency in industry sector. Energy Policy 39 (10), 6532-6550.

Thollander, P., Ottosson, M., 2010. Energy management practices in Swedish energy-intensive industries. Journal of Cleaner Production 18 (12), 1125-1133.

Thollander, P., Palm, J., 2012. Improving energy efficiency in industrial energy systems: An interdisciplinary perspective on barriers, energy audits, energy management, policies, and programs. Springer, London.

Tranfield, D., Denyer, D., Smart, P., 2003. Towards a Methodology for Developing Evidence-Informed Management Knowledge by Means of Systematic Review. British Journal of Management 14. 207-222.

Trianni, A., Cagno, E., De Donatis, A., 2014. A framework to characterize energy efficiency measures. Applied Energy 118, 207-220.

Vasudevan, S., Higgins, B., 2004. Strategic Energy Risk Management for End Users. The Journal of Structured and Project Finance 10 (1), 74-78.

Virtanen, T., Tuomaala, M., Pentti, E., 2013. Energy efficiency complexities: A technical and managerial investigation. Management Accounting Research 24 (4), 401-416.

Worrell, E., Laitner, J. A., Ruth, M., Finman, H., 2003. Productivity benefits of industrial energy efficiency measures. Energy 28 (11), 1081-1098.

Worrell, E., Price, L., 2006. An Integrated Benchmarking and Energy Savings Tool for the Iron and Steel Industry. International Journal of Green Energy 3 (2), 117-126.

Zhang, J., Wang, G., 2008. Energy saving technologies and productive efficiency in the Chinese iron and steel sector. Energy 33 (4), 525-537. 